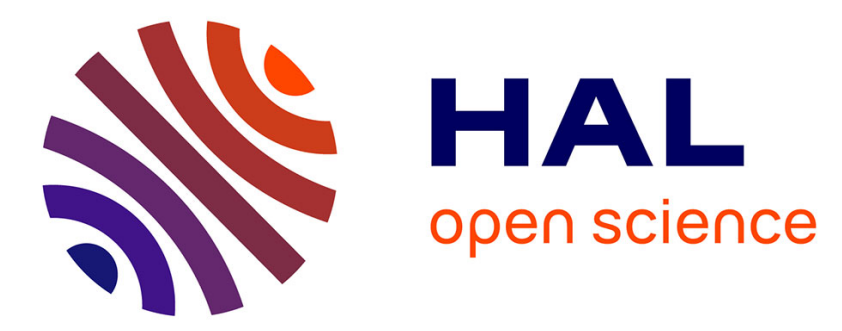

\title{
Surface engineering of polystyrene-cerium oxide nanocomposite thin films for refractive index enhancement
}

\author{
Jemy James, Aparna Beena Unni, Khadidja Taleb, Jean-Paul Chapel, \\ Nandakumar Kalarikkal, Soney Varghese, Guillaume Vignaud, Yves Grohens
}

\section{To cite this version:}

Jemy James, Aparna Beena Unni, Khadidja Taleb, Jean-Paul Chapel, Nandakumar Kalarikkal, et al.. Surface engineering of polystyrene-cerium oxide nanocomposite thin films for refractive index enhancement. Nano-Structures and Nano-Objects, 2019, 17, pp.34-42. 10.1016/j.nanoso.2018.11.001 . hal-02121258

\section{HAL Id: hal-02121258 \\ https://hal.science/hal-02121258}

Submitted on 12 Nov 2020

HAL is a multi-disciplinary open access archive for the deposit and dissemination of scientific research documents, whether they are published or not. The documents may come from teaching and research institutions in France or abroad, or from public or private research centers.
L'archive ouverte pluridisciplinaire HAL, est destinée au dépôt et à la diffusion de documents scientifiques de niveau recherche, publiés ou non, émanant des établissements d'enseignement et de recherche français ou étrangers, des laboratoires publics ou privés. 


\section{Surface Engineering of Polystyrene-Cerium Oxide}

\section{Nanocomposite Thin Films for Refractive Index}

\section{Enhancement}

Jemy James ${ }^{i, \AA}$, Aparna Beena Unni ${ }^{k}$, Khadidja Taleb ${ }^{\varsigma}$, Jean-Paul Chapel ${ }^{k}$, Nandakumar

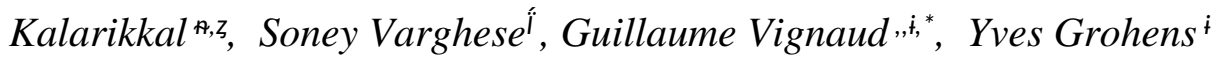

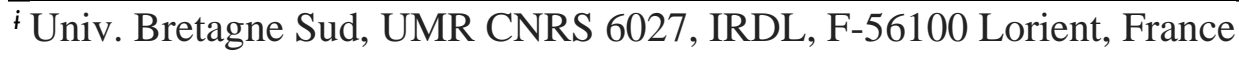

${ }^{n}$ International and Inter University Centre for Nanoscience and Nanotechnology, Mahatma

Gandhi University, Kottayam, Kerala, 686560 India

${ }^{k}$ NSS College of Engineering, Palakkad, Kerala, India

${ }^{\circledR}$ Université Oran 1 Ahmed Ben Bella, Laboratoire de Synthèse Organique Appliquée (LSOA),

Département de Chimie, Faculté des Sciences Exactes et Appliquées, BP 1524 EL Mnaouer,

31000 Oran, Algeria

${ }_{3}^{3}$ School of Pure and Applied Physics, Mahatma Gandhi University, Kottayam, Kerala, 686560

India

${ }^{\star}$ Centre de Recherche Paul Pascal (CRPP), UPR 8641, CNRS, F-33600 Pessac, France

Î́School of Nano Science and Technology, National Institute of Technology, Calicut 673 601,

Kerala, India 

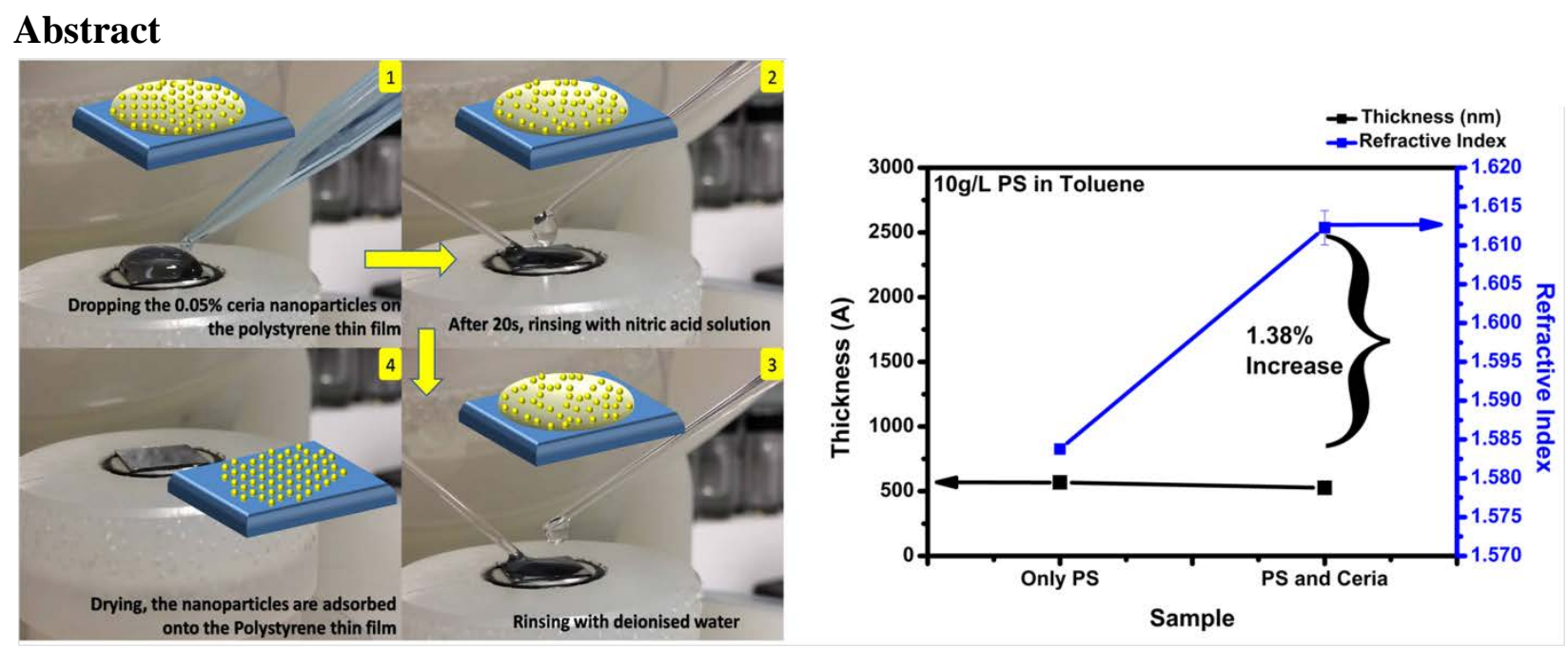

Polymer nanocomposites have gained much importance in the field of optoelectronics due to their unique optical properties. Refractive index engineering using nanoparticles is an effective strategy that could be applied for the fabrication of optical devices. Herein, we report three different strategies which are employed to enhance the refractive index of polymer thin films. These include incorporating cerium oxide nanoparticles onto the polystyrene matrix, secondly adding cerium oxide nanoparticles onto the cross-linkable polystyrene and thirdly by embedding functionalized cerium oxide nanoparticles onto the cross-linkable polystyrene. Refractive index of the polystyrene thin films was enhanced by dispersing neat $\mathrm{CeO}_{2}$ nanoparticles and functionalized $\mathrm{CeO}_{2}$ nanoparticles into the polystyrene matrix. $1.38 \%$ enhancement in the refractive index of the polymer nanocomposite thin films could be achieved using our technique. The blending of polystyrene with cerium oxide nanoparticle presents a prospective way to engineer the refractive index of polymer thin films. We firmly believe that the study will be an effective guide towards future research in the area of surface engineering of polymer thin films for refractive index enhancement.

Keywords:

Thin films; Polymer nanocomposites; Refractive Index; Surface engineering; Polystyrene; Cerium oxide 


\section{Introduction}

The development and advances in photonic gadgets are becoming more dependent on the availability of new functional materials, as these devices are gaining more importance in daily life in the form of sensors, light sources and energy harvesters ${ }^{1-5}$. An important characteristic of a material, that can be used in optical design, is its refractive index. Refractive index engineering is significant for photonic integrated circuits (PIC) fabrication and other applications, and the scientific community has been working on materials with refractive index ranging from positive refractive index ${ }^{6-8}$ to negative refractive index ${ }^{9-11}$.

The search for better light sources since the energy crisis of the 1970's, led to the emergence of Light Emitting Diodes (LED). Reducing the refractive index mismatch between the semiconductor used in the LED and the LED encapsulant increases the light extraction from the LED. Even a small enhancement in the LED efficiency could be beneficial considering the multifaceted application of LED's world wide.. There are also some areas where the refractive index mismatch is taken advantage of, like in the area of semiconductor lasers (distributed Bragg reflectors), where the change in refractive index leads to reflection, which increases the oscillation of the light being generated inside the cavity of the laser ${ }^{12}$. Surface modified nanoparticles are being used along with the encapsulant for the enhanced performance of the LEDs ${ }^{13}$.

There is an increase in the need for optical materials with high refractive index for the manufacturing of filters, optical waveguides, photonic crystals, optoelectronics devices ${ }^{7}$, etc. Inorganic materials have high refractive indices, but some of their disadvantages like lack of flexibility and higher density have led researchers to look towards organic materials, which have lower weight, ease of processability of fabrication of devices, lower cost of processing, good flexibility and better impact resistance compared with inorganic materials ${ }^{8,14,15}$. Also, the recyclability of polymers makes them an environmentally friendly alternative in contrast to inorganic materials ${ }^{16,17}$. The conventional organic polymer materials have a low refractive index of $1.4 \sim 1.6$ at a given wavelength of $600 \mathrm{~nm}^{18}$. High refractive index polymers with high transparency ${ }^{14}$ are in demand these days due to advancements in the optoelectronic industry, like ultra-fast data transmission ${ }^{15}$, advanced sensors ${ }^{19,20}$, display devices, microlenses for imaging applications, biomedical applications ${ }^{21,22}$ etc. Some of the polymers 
like poly(thiophene) and aromatic polyamides have high refractive index values of 2.12 and 1.57-2.05 at a wavelength of $632 \mathrm{~nm} \mathrm{21,23-27}$. But some of these polymers need to be synthesized from monomers. Apart from the difficulty in the preparation of these kinds of polymer materials, some of these high index polymers absorb light in the visible region, have high optical dispersion and tend to be insoluble due to the presence of aromatic type highly conjugated $\pi$-electron structure ${ }^{7}$. These limit their potential for use in practical optical applications and thus the development of high refractive index organic materials with better optical properties and related characteristics remains a challenge.

Polymer thin films can be prepared so as to study their properties and for specific applications, as mentioned earlier. Confinement effects on polymer thin films can be exploited to tune the refractive index. Vignaud et al. have shown that it is possible to increase/decrease the refractive index of polystyrene(PS) and poly(methyl methacrylate)(PMMA) thin films by reducing the film thickness ${ }^{28,29}$. In a similar way, Huang reported the development of polymer metal oxide hybrid films, with tunable refractive index ${ }^{30}$.

An enhancement in the refractive index can be achieved by incorporating nanoparticles into the polymer matrix, an approach which opens up many avenues for existing and potential applications, due to their improved thermal, optical, mechanical and optoelectronic properties and due to the simpler synthesis techniques, in contrast to the conventional synthesis of high RI polymers as mentioned earlier ${ }^{31-34}$. The incorporation of high refractive index inorganic building blocks, for example, metal oxides and metal chalcogenide semiconductor nanoparticles into the organic matrix is an effective way to increase the refractive index without diminishing the optical transparency ${ }^{35,36}$.

Numerous studies have focused on the physical properties of polymer thin film nanocomposites ${ }^{37-44}$. The mobility and thermodynamic properties of polymer nanocomposites, when confined at nanometre length scales, differ greatly from properties in the bulk ${ }^{37-41}$. For example, Boucher et al. reported the effects of gold nanoparticles on the ageing, glass transition temperature and dynamics of polystyrene thin films ${ }^{42}$. In this study, of the thin nanocomposite films, it was found that an increase in the amount of gold nanoparticles decreases the calorimetric glass transition temperature and accelerates the 
physical ageing of the polystyrene thin films. Such behaviour could be attributed to the interactions existing between the polymer and the nanoparticles. Similarly, recent studies have shown that addition of nanoparticles to polymer films improves its stability against dewetting ${ }^{43}$. It is believed that segregation of the nanoparticles at the interface alters the interfacial energy. This in turn results in the enhancement of the stability of thin films. In another study by the research group of Chandran, the effect of confinement on the dispersion of the nanoparticle was studied ${ }^{44}$. The dispersion is enhanced without altering the polymerparticle interactions due to the increased matrix-chain orientation propensity. Regarding the optical properties, the recent article by Matsumoto and group mentions about the development of colourless, transparent, high refractive index polymer composite films of polyvinyl alcohol (PVA) and tungstophosphoric acid (PWA) ${ }^{45}$. Highly transparent mesoporous polymer thin films were obtained by UV curing, in which the refractive index could be tuned by adjusting the filler content ${ }^{46}$. Krogman et al. demonstrated that it is possible to fabricate polymeric thin films of continuously tunable refractive index over a wide range by loading the film with varying concentrations of metal oxide nanoparticles ${ }^{47}$. Surface modified titanium dioxide nanoparticles were used to enhance the refractive index of the organic-inorganic hybrid film ${ }^{48}$. Preparation of multilayered films with variable refractive index can lead to the development of thin films with desired refractive index ${ }^{49-52}$.

Polystyrene is a transparent polymer in the visible region and has a higher refractive index of 1.59 at a wavelength of $632 \mathrm{~nm}$ and is less expensive. Cerium oxide nanoparticles have a refractive index of 2.2 at a wavelength of $632 \mathrm{~nm}$ and are transparent in the visible region ${ }^{53}$.

In the present study, polystyrene thin films were prepared using spin coating and cerium oxide nanoparticles were incorporated in the polystyrene matrix through three different methods so as to increase the refractive index of the formed nanocomposite thin film. Though there are polymers with high refractive index, the versatility and ease of processability of the polystyrene make it a unique choice for our experiment. The first technique for preparing the polymer nanocomposite was to deposit cerium oxide(ceria) nanoparticles onto the polystyrene thin film ${ }^{29}$, the second method was to incorporate the ceria nanoparticle onto the cross-linkable polystyrene thin film ${ }^{50}$, while in the third method functionalized ceria nanoparticles were bulk mixed to the cross-linkable polystyrene ${ }^{54}$ and the composite solution was spin coated to prepare the thin film. The refractive index and the 
thickness of the prepared thin films were measured using ellipsometry and atomic force microscopy was used to understand the morphology of the thin films. The previously reported work on polystyrene ceria involved bulk mixing of the ceria nanoparticles into the polystyrene matrix ${ }^{54,55}$. The approaches towards surface deposition of the ceria nanoparticle for refractive index modification had not been commonly used and this article introduces these novel techniques to engineer the refractive index of polymer thin films. To our knowledge, this facile approach has proved to be an efficient strategy, to enhance the refractive index of the thin films, to a great extent, without much complication, which opens up a plethora of applications.

\section{Materials and Methods}

\subsection{Materials}

Polystyrene (P10447-S), with a molecular weight of 135,800 g/mol, and a polydispersity index of 1.05, was procured from Polymer Source, Canada. Azide terminated polystyrene, with a molecular weight of $15,000 \mathrm{~g} / \mathrm{mol}$ and polydispersity index of 1.3 , hydrogen peroxide $\left(\mathrm{H}_{2} \mathrm{O}_{2}\right)(35$ wt \%), sulphuric acid $\left(\mathrm{H}_{2} \mathrm{SO}_{4}\right)(98 \%)$, and hydrofluoric acid (HF) were purchased from Sigma Aldrich. Cerium oxide $\left(\mathrm{CeO}_{2}\right)$ nanoparticles were supplied by Rhodia-Solvay chemicals (Belgium). The nanoparticles had a log-normal size distribution with a mean diameter of $8.3 \mathrm{~nm}$ and polydispersity index of 0.26 , measured by Dynamic Light Scattering. The stability of the nanoparticles was maintained at a $\mathrm{pH}$ of 1.5 , by balancing the electrostatic forces and the hydration interactions ${ }^{56}$.

\subsection{Substrate preparation}

The silicon wafers were diced into individual pieces of dimensions $1 \times 1 \mathrm{~cm}^{2}$. They were immersed in piranha solution, so as to remove any organic contamination. The details regarding the piranha treatment are available in the literature ${ }^{57}$. After the treatment, the substrates were rinsed with Milli-Q water (of resistivity $\sim 18.2 \mathrm{M} \Omega \mathrm{cm}$ ) and were dried. The oxide layer on the wafers was removed through $\mathrm{HF}$ treatment, where the samples were immersed in 5\% $\mathrm{HF}$ solution for 5 minutes, prior to spin coating ${ }^{58}$. The Piranha treatment results in having hydroxyl groups on the substrate surface whereas the HF treatment removes the thin native oxide on the surface $^{29,57,59}$. 


\subsection{Sample Preparation}

The polymer thin films sample preparation was carried out in various steps and different modalities were employed to prepare the samples as mentioned below.. This was carried out to explore various possibilities in the preparation of polymer thin films with higher refractive index and with good transparency. A simple schematic of the preparation modalities is shown in Figure 1. A spin coating machine, SPS Spin 150i, was used for coating the thin films.

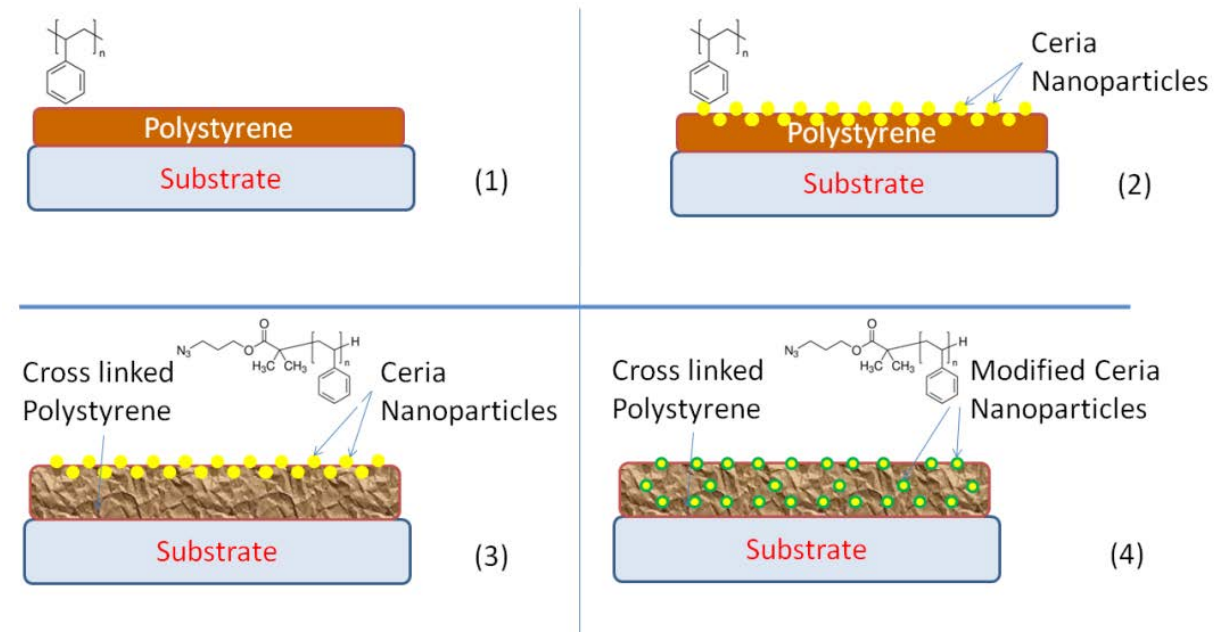

Figure 1: A schematic showing various modalities employed to prepare the thin films

\subsection{Preparation of neat polystyrene thin films}

As a first step, neat polystyrene thin films, without any doping of nanoparticles, were prepared. Polymer solutions with a mass concentration $10 \mathrm{~g} / \mathrm{L}$ in anhydrous toluene (99.8\%) were prepared and kept aside for $24 \mathrm{~h}$ for better polymer dissolution. Prior to spin coating, the solution was filtered using a $200 \mathrm{~nm}$ poly tetra fluoro ethylene (PTFE- Teflon) syringe filter and was spin coated onto the prepared substrate at a rotation speed of $2000 \mathrm{rpm}$ for 60 seconds. The films were then annealed at $160^{\circ} \mathrm{C}$ for $24 \mathrm{~h}$ in a vacuum oven. Similarly, the thin films were prepared using polystyrene solutions with mass concentration of $20 \mathrm{~g} / \mathrm{L}$ in anhydrous toluene. A representative image of the prepared thin film is shown in figure 1 (1)Toluene is used when compared to other low boiling point solvent such as Tetrahydrofuran (THF), as the low boiling point solvent get evaporated very fast such that the rapid evaporation of the solvent during the spin coating process itself leaves behind, pores or holes due to the vapour and thus the film get perforated ${ }^{60}$. It is not ideal for this kind of application as for ellipsometry, a smooth thin film is always preferable than a rough 
film. Also, the compatibility of toluene with PS is higher considering THF considering the Hansen's solubility parameter. THF also posses polarity which can affect the stability of the films ${ }^{56}$.

\subsection{Preparation of cerium oxide nanoparticle decorated polystyrene thin films}

Polystyrene thin films were prepared and the deposition of nanoparticles on the thin film was the next hurdle. The polymer films were prepared as before. The cerium oxide (ceria) nanoparticles dispersions $(0.05 \mathrm{wt} \%)$ were dropped over each prepared polystyrene thin film and were allowed to be adsorbed for $20 \mathrm{~s}\left(100 \mu \mathrm{l}\right.$ droplet was used for each 1 x $1 \mathrm{~cm}^{2} \mathrm{Si}$ wafer). To increase the nanoparticle (NP) adsorption density, $0.1 \mathrm{M}$ of $\mathrm{NaNO}_{3}$ has been added in the solution to screen the inter NP repulsive interaction. The solution was then removed as shown in the figure 4 and the surface was rinsed with pure nitric acid of $\mathrm{pH} 1.5$ and later on, the surface was rinsed with distilled water. The intermediate cleaning step with nitric acid was carried out to prevent any kind of precipitation of the nanoparticles that can occur when the $\mathrm{pH}$ suddenly changes when it is washed with water. The films were then annealed at $160{ }^{\circ} \mathrm{C}$ for $24 \mathrm{~h}$ in a vacuum oven. Figure $1(2)$ is a representative image of the samples prepared.

\subsection{Preparation of cross-linked polystyrene-cerium oxide nanoparticle thin films}

Cross-linking is a process in which the individual chains of the polymers are linked to one another through initiating mechanism, be it chemical initiators or optical initiators ${ }^{50,61}$. Azide terminated crosslinkable polystyrene was used to prepare the polymer solution for crosslinking in which the solution had a mass concentration of $10 \mathrm{~g} / \mathrm{L}$ polystyrene in anhydrous toluene (99.8\%). The solution was prepared and kept aside for $24 \mathrm{~h}$ for better polymer dissolution. The solution was protected from external light by storing it in a covered container. The polymer thin films were prepared as mentioned before. After spin-coating, the thin films were cross-linked by UV curing (BioforcePro-Cleaner, $\lambda=365 \mathrm{~nm}, 460 \mu \mathrm{W} \mathrm{cm}{ }^{-2}$, the distance between sample and UV lamp $=8 \mathrm{~mm}$ ) for 30 minutes followed by two hours of annealing at $180{ }^{\circ} \mathrm{C}$. Figure 1(3) shows a representative image of the sample prepared.

\subsection{Preparation of cross-linked polystyrene- embedded with modified ceria oxide nanoparticle thin films}

There have been reports of cross-linked hybrid multilayer thin films from azido functionalized polystyrene and nanoparticles ${ }^{50,62}$. The cerium oxide nanoparticles were modified with MPS(3- 
(Trimethoxysilyl)propyl methacrylate) by using the method mentioned elsewhere ${ }^{63}$. The capping of the ceria nanoparticles with MPS makes it more stable and less prone to agglomeration. The modified nanoparticles were mixed in the cross-linkable polystyrene solution of mass concentration of $10 \mathrm{~g} / \mathrm{L}$ in toluene and the solution was kept aside for 24 hours in a covered container to protect it from light and for better polymer dissolution. The solution was filtered using a $200 \mathrm{~nm}$ PTFE syringe filter prior to spin coating. The spin-coated samples were UV cured for 30 minutes before annealing at $180{ }^{\circ} \mathrm{C}$ for 2 hours.

\subsection{Characterization}

Ellipsometry is a non-destructive technique, which allows for analysis of optical properties of thin films, including thickness and refractive index ${ }^{29,64}$. This technique depends on the changes in polarization state of the light, after reflecting from a thin film. A spectroscopic ellipsometer (Horiba Jobin Yvon, UVISEL instrument), which has a xenon lamp as the light source, with a spectral range between $190 \mathrm{~nm}$ and $2100 \mathrm{~nm}$, was used to measure the thickness and refractive index of the thin films. The instrument is controlled by DeltaPsi2 software platform. The measurements were all taken at ambient conditions (55\% of relative humidity and at an ambient temperature of $20^{\circ} \mathrm{C}$ ). The refractive index spectrum $\mathrm{n}(\lambda)$ for all the films was fitted using a single layer model which consisted of a polymer layer and a silicon substrate. The fitting parameters were the refractive index of the polymer film and the angle of incidence. The refractive index of the polymer film was modelled using a transparent Sellmeier dispersion relation in the DeltaPsi2 software. The calculated optical constants and the thicknesses were determined by simultaneous fitting of the data obtained at three different incident angles $\left(65^{\circ}\right.$, $70^{\circ}$ and $75^{\circ}$ ). The error for each angle was given from the fitting of the model and the measured data by the ellipsometry software. And the error bar used in the graph is from the software (fitting) and from the diversity of studied samples. The refractive indices can be measured with an absolute error of $0.002^{20}$.

The topography of the films was studied using an Atomic Force Microscope (Multimode, NanoscopeIIIa) in tapping mode of operation. In the AFM, a nanometre size tip, on a cantilever, scans the sample surface and the tip is attracted to or repelled by the surface of the sample by the intermolecular interactions (forces) between the atoms of the tip and the surface, leading to a deflection in the cantilever. The deflection of the cantilever is measured. The tip used had a resonant frequency of $300 \mathrm{kHz}$, and a spring constant of $40 \mathrm{~N} / \mathrm{m}$. The film thickness can also be 
measured using the AFM by making a scratch on the sample and scanning the scratch perpendicularly using the AFM tip ${ }^{65}$.

\section{Results and discussion}

\subsection{Analysis of the neat polystyrene thin films}

The thickness and refractive index of the neat polystyrene thin films prepared using spin-coating was studied using ellipsometry. The measured thickness and refractive index of the sample are shown in figure 2 . The average thicknesses of the samples prepared using polystyrene solution of mass concentrations of $20 \mathrm{~g} / \mathrm{L}$ in toluene were found to be $1050 \AA$ and the average refractive index was observed to be around 1.58 at $632 \mathrm{~nm}$. The reliability of the data was observed by repeating measurements on different samples prepared using the same techniques. Similarly, the thickness of the thin films prepared using polystyrene solutions of mass concentrations of $10 \mathrm{~g} / \mathrm{L}$ in toluene was measured to be $455 \AA \AA$ and the refractive index was ascertained to be around 1.593 at $632 \mathrm{~nm}$. The refractive index was found to be in agreement with that of reported literature ${ }^{28}$.

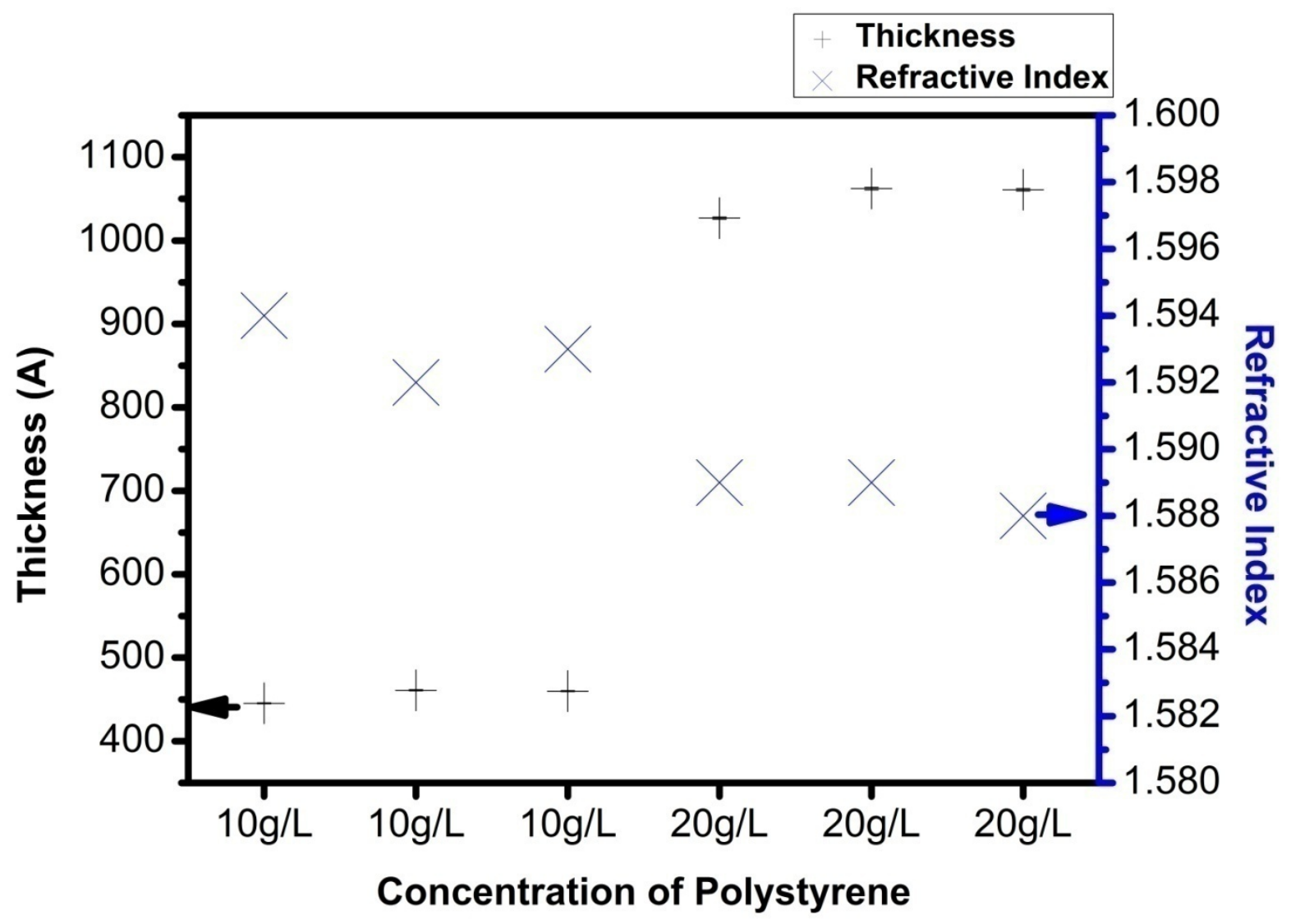


Figure 2: The thickness and refractive index measurement of the polystyrene thin films prepared at a mass concentration of $10 \mathrm{~g} / \mathrm{L}$ and $20 \mathrm{~g} / \mathrm{L}$ of polystyrene in toluene, ( the error bar is too low to be visible, the arrow indicates the corresponding measurement).

As it is observed, the refractive index is found to increase with the reduction in thickness of the polymer film. An increase in the density correlated with a decrease of the PS film thickness is in line with previous experimental findings $\mathrm{s}^{28,29,59,66}$. As mentioned earlier, the thinner films of the polymer were prepared by using less concentrated (10 g/L) polymer solutions. A schematic regarding this is shown in Figure 3.This renders lower entanglement of the polymer chains thereby leading to a higher order of orientation of the polymer chains because of the stronger polymer-solvent, polymer-polymer, and polymer-substrate interactions. Highly ordered polymer chains result in a higher density of the polymer chains leading to an enhancement in the refractive index ${ }^{67-69}$.

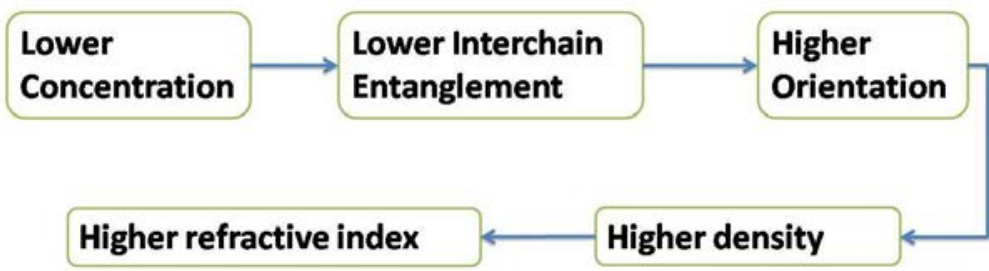

Figure 3: Schematic of the increase in refractive index with the reduction in the thickness

\subsection{Analysis of the nanoparticle deposited polystyrene thin films}

The polystyrene thin film was also prepared by spin coating the polystyrene solution of mass concentration of $10 \mathrm{~g} / \mathrm{L}$ in toluene. Cerium oxide nanoparticles were dropped onto the thin films using the method mentioned earlier and the films were annealed. The scheme of the procedures used to deposit the ceria oxide nanoparticles is depicted in figure 4. 


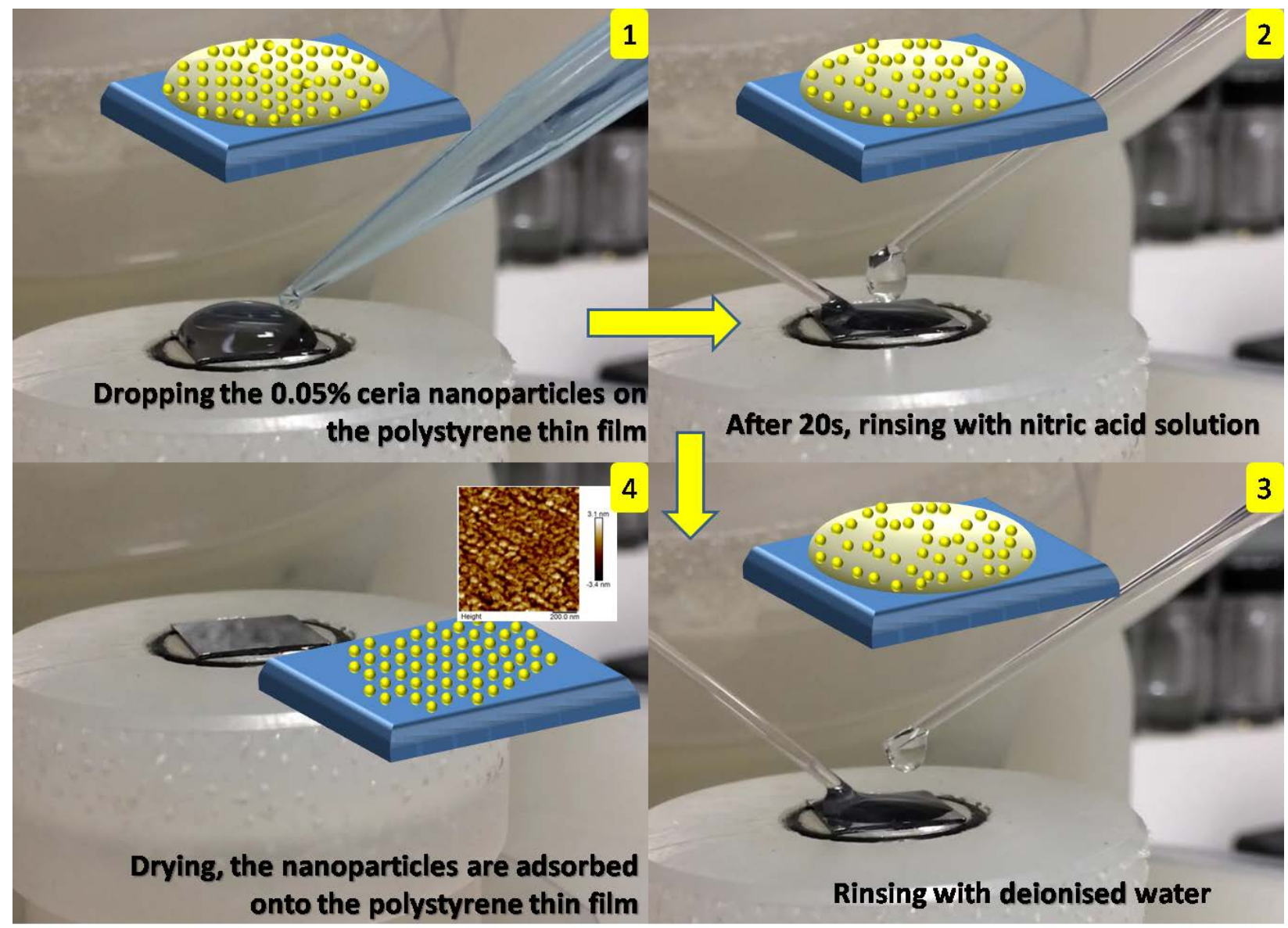

Figure 4: Steps involved in the deposition of the cerium oxide nanoparticles on the polystyrene thin films (The inset in part 4 shows the AFM image of a sample prepared)

The annealing was carried out at $160 \operatorname{deg} \mathrm{C}$ for 24 hours so as to remove the entrapped solvent molecules 70. In addition, fast solvent evaporation used in the spin-coating process can lead to non-equilibrium conformations of the polymer chains. As a result, the chains are trapped in distorted conformations with a reduced degree of interchain overlap introducing residual stresses into the film. This might contribute to alter the chains dynamics ${ }^{71}$. The annealing the thin film, well above the glass transition temperature leads to a relaxed polymer thin film ${ }^{72}$.

The thickness and the refractive index of the thin films were measured using ellipsometry and are shown in figure 5. The thickness of the samples dropped with ceria was found to be $567 \AA$ and the samples without ceria were found to have a thickness of $525.5 \AA$. The refractive index of the neat samples as measured by ellipsometer was 1.59, whereas the ceria nanoparticles dropped 
polystyrene thin film had an enhanced refractive index of 1.612 and it is attributed to the presence of the ceria nanoparticles ${ }^{73}$. As it has been reported, a hybrid composite containing, an organic polymer and a high refractive index inorganic nanoparticle could achieve $1.38 \%$ higher refractive index value ${ }^{16}$. The AFM images of the polystyrene thin film sample with ceria nanoparticles dropped onto it is shown in figure 6. The increase in the refractive index, as measured from ellipsometry is also justified by the presence of ceria nanoparticles as observed from the AFM images.

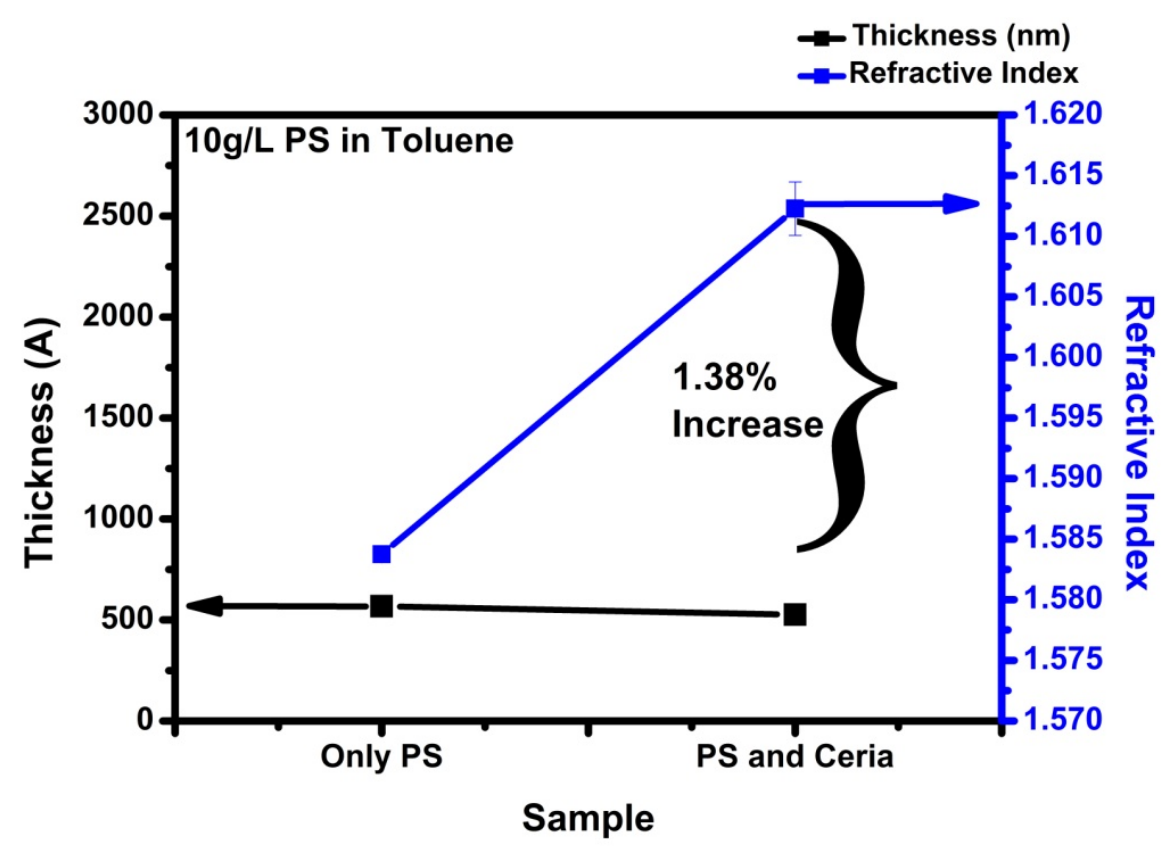

Figure 5: The thickness and refractive index measurement data of polystyrene samples without (only PS) and with ceria nanoparticles dropped on it (the error bar of the refractive index of the only PS is too low to be visible). 


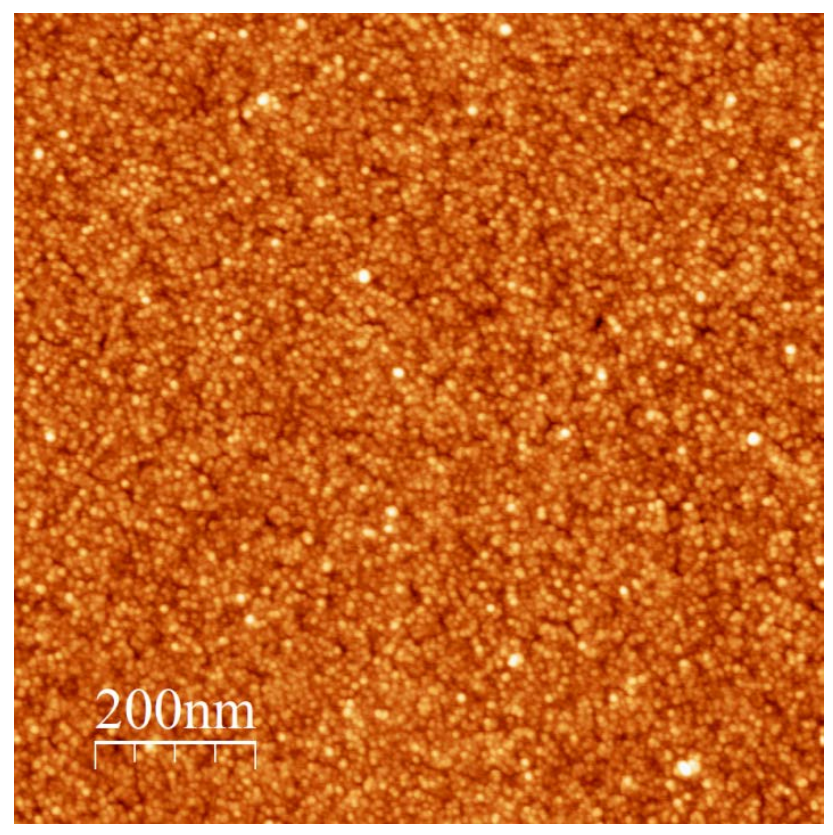

Figure 6: AFM image of the ceria dropped polystyrene thin film.

\subsection{Analysis of cross-linked polystyrene-ceria thin films}

The polystyrene thin films can be prone to leaching when these films are placed in or are exposed to solvents. Cross-linking of the polystyrene overcomes this limitation, as it retards or inhibits any kind of dewetting or leaching. Digital photographs of the samples, before and after crosslinking are shown in figure 7 . The UV curing of the thin films leads to the change in the colour of the thin films from dark blue to golden yellow. This change in colour can be attributed to the reduction in the thickness of the samples after cross-linking due to the increased molecular density of the composite films ${ }^{74-76}$. UV cross linking of the polystyrene is carried out in room temperature, which leads to the covalent stabilization of the of the polymer chains. Also, the chemically inert azide group get activated by heat or light which lead to the formation of highly reactive nitrene groups, which initiate the reaction with neighbouring groups leading to cross linking..$^{50,62}$ 

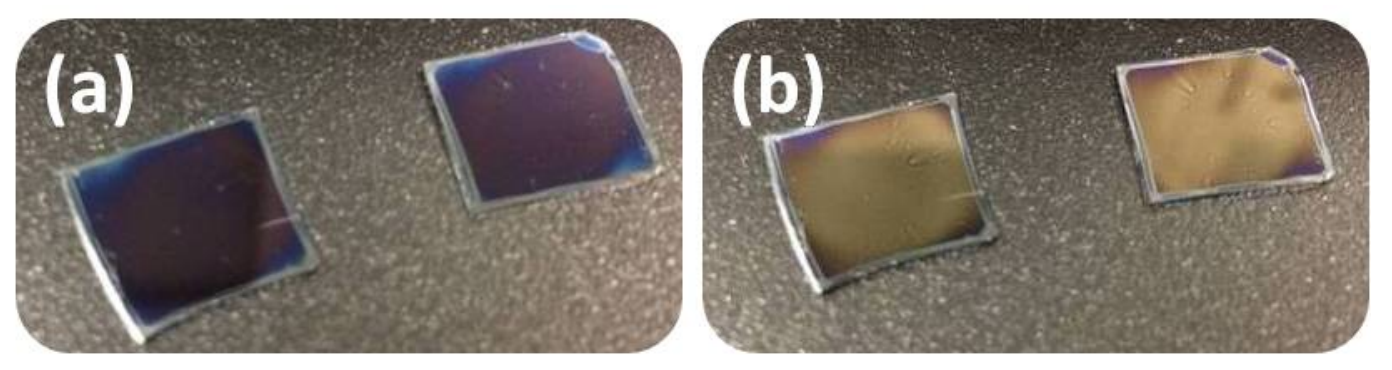

Figure 7: Digital Photograph of the samples, before UV curing, showing bluish violet colour (a) and after UV curing, showing golden yellow colour (b).

The ellipsometric measurements have been carried out to ascertain the thickness of the thin films and the result is shown in Table 1. As it can be seen from the graph, the thickness of the sample decreased, almost $50 \%$ on UV curing. UV curing results in an increase in the molecular density of the thin films. This causes the films to shrink and hence the thickness is reduced ${ }^{75}$. The sample thickness was also measured using the AFM and the result is in agreement with the ellipsometry measurements. The measurement data is shown in Table 1. In the case of AFM, a sharp scratch was made on the sample surface and the tip of the AFM was scanned perpendicular to the scratch to measure the thickness ${ }^{65}$. The cross-linked samples were more resistant to scratch when compared to the non cross linked samples when a scratch was made on the surface of the sample using a needle. A schematic of the process of reduction in the thickness of the crosslinked polystyrene thin film is demonstrated in figure 8.

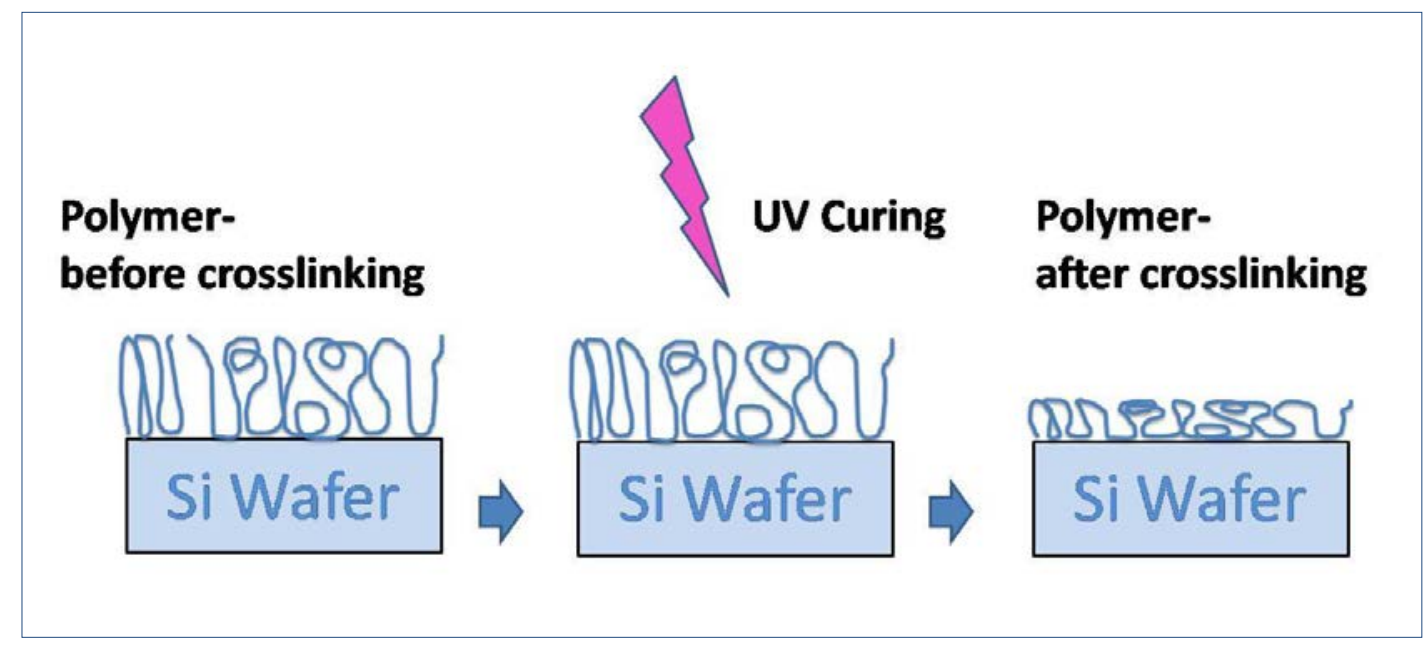

Figure 8: A schematic showing the reduction in the thickness after cross-linking 
Table 1: Thickness measurements using ellipsometry and AFM

\begin{tabular}{|c|c|c|}
\hline $\begin{array}{l}\text { Sample - Crosslinked or non- } \\
\text { crosslinked }\end{array}$ & $\begin{array}{l}\text { Thickness measured using } \\
\text { ellipsometry (Á) (error bar in } \\
\text { brackets) }\end{array}$ & $\begin{array}{l}\text { Thickness measured using } \\
A F M(\hat{A})\end{array}$ \\
\hline Non-Crosslinked-1 & 852 (1.6) & 800 \\
\hline Non-Crosslinked-2 & $867(0.4)$ & 870 \\
\hline Cross-linked 1 & $416(7.7)$ & 450 \\
\hline Cross-linked 2 & $500(0.9)$ & 470 \\
\hline
\end{tabular}

The stability of polymer thin films, on substrates, is of prime significance in the area of semiconductors, optoelectronic devices etc. In ultrathin films, typically thinner than $100 \mathrm{~nm}$, the issue of film stability becomes important as these films often become unstable and tend to rupture and dewet following a variety of mechanisms such as spinodal dewetting engendered by the van der Waal's interaction, heterogeneous nucleation, and so on ${ }^{75,77}$. By cross-linking the polymers, the strong physical interactions between the polymer chains increase the viscosity of the film and inhibit the dewetting process when the thin film is heated above the glass transition temperature or exposed to solvent vapour. The optical microscopic images of the films, crosslinked and non crosslinked are shown in figure 9. It can be seen that the crosslinked samples have lower dewetting when compared to the non-crosslinked samples. Akhrass et al. studied the influence of the cross-linking density on film dewetting ${ }^{78}$. When partial cross-linking occurred in a film with a lower molar mass, the effective molar mass of the polymer increased, and an increase in the relaxation time was observed. For the higher molar mass polymer, no changes in the relaxation time were observed for the partially cross-linked film. For a high crosslinking density, the relaxation time increased dramatically which suggested an almost infinitely long relaxation time. 


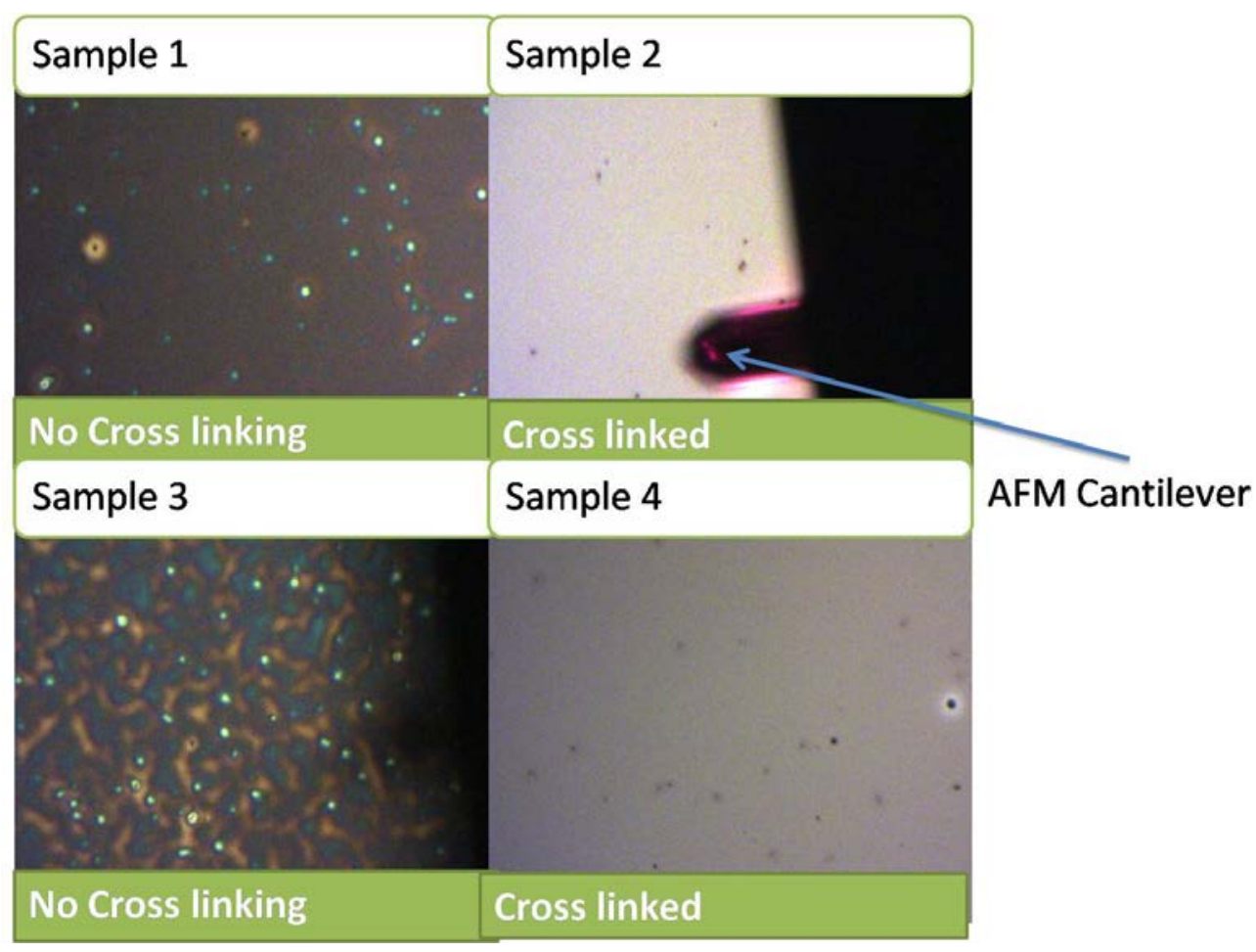

Figure 9: Optical Microscopic images showing the effect of cross-linking in preventing the dewetting of the thin polystyrene films after thermal annealing in a vacuum oven. Thin films of the azide terminated cross-linkable polystyrene with $10 \mathrm{~g} / \mathrm{L} \mathrm{wt} \%$ in toluene was prepared and ceria nanoparticles were deposited on the thin film for $20 \mathrm{~s}$ before UV curing and subsequent annealing. 


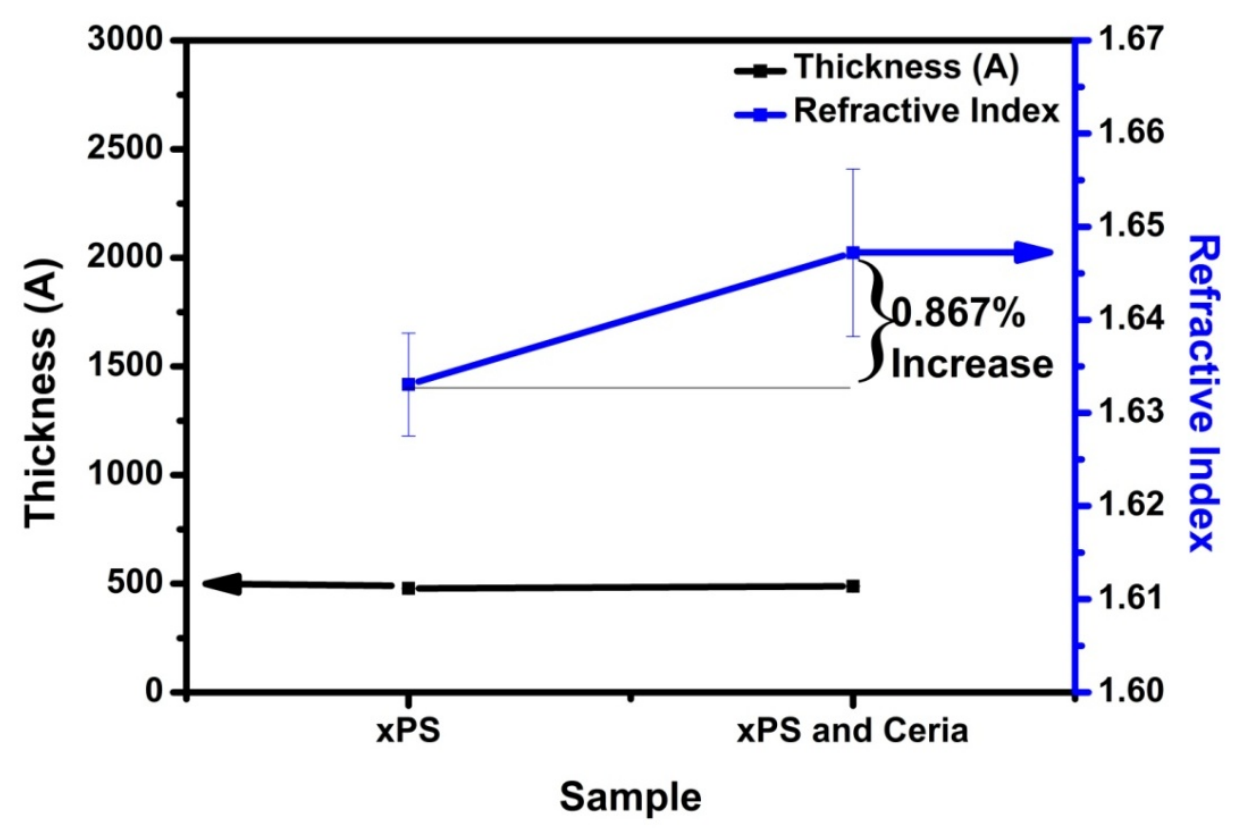

Figure 10: Thickness and refractive index of crosslinked polystyrene-ceria nanocomposite thin films(the error bar of the thickness is too low to be visible)

The ellipsometric measurement results, shown in figure 10, indicate that the refractive index increased on addition of the ceria nanoparticle. Though there is a slight increase of the refractive index on cross-linking, the addition of the ceria nanoparticle resulted in $0.87 \%$ enhancement on the refractive index of the composite thin films. The refractive index increases due to the formation of the highly cross-linked network by a densification effect. The reduction in the distance between polymer chain led to the reduction in the free volume which in turn resulted in the densification effect.

\subsection{Analysis of the cross-linked polystyrene-modified ceria thin films}

The approach to prepare this nanocomposite is different from the earlier methods used. The surface modified ceria nanoparticles were dispersed into the polystyrene solution of toluene (10 wt\% PS) and kept overnight in the dispersed state. The bulk mixing of the cerium oxide nanoparticles and the polystyrene have led to the better dispersion of the nanoparticles on the thin film. 


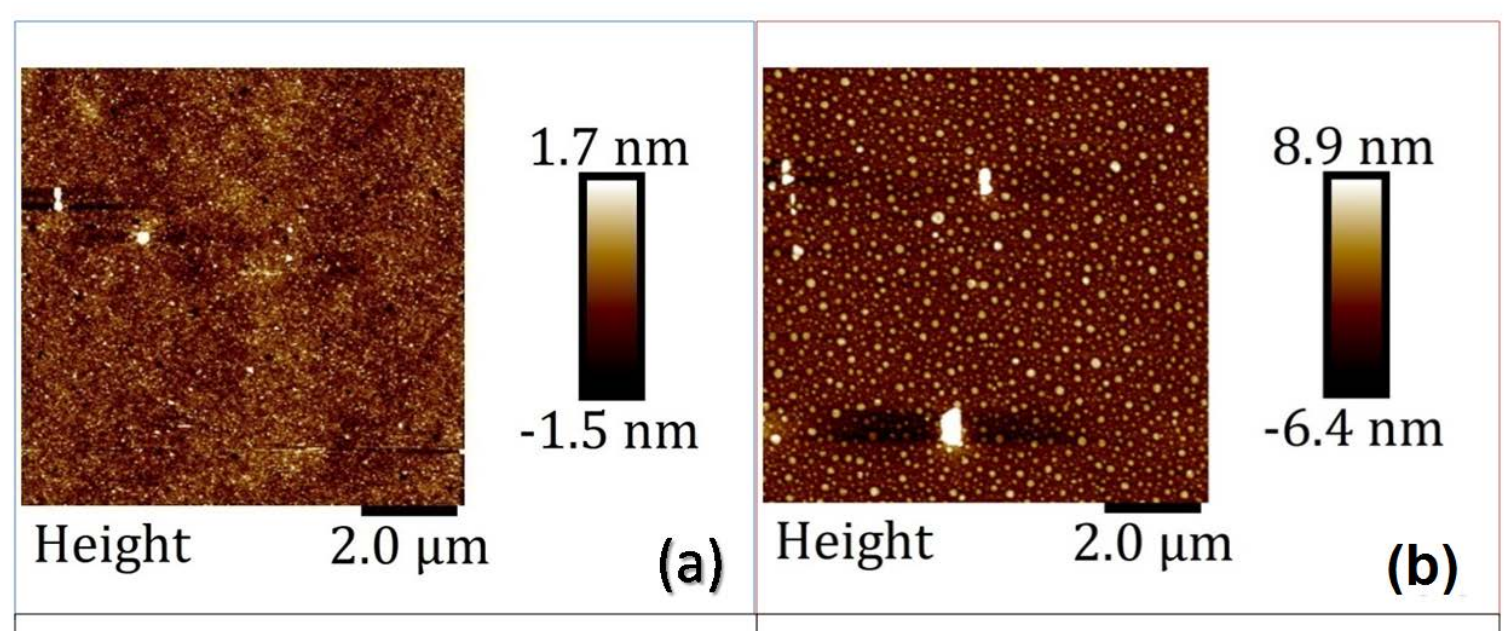

Figure 11: AFM images of the crosslinked polystyrene thin film (a), AFM image of the MPS modified Ceria nanoparticle- cross-linked polystyrene nanocomposite thin film (b)

AFM images (figure 11) show that the polystyrene ceria nanocomposite prepared using the modified ceria nanoparticles had a uniform distribution of the particles and the ellipsometric measurements clearly indicate an increase in the refractive index(figure 12). It should be noted that the sample without the nanoparticles had a refractive index of 1.635 and the refractive index of the sample with the modified nanoparticles is 2.018 . Hence this increase cannot be attributed to cross-linking or thickness of the thin film alone. The enhancement in the refractive index is based on the effective medium models, where the average refractive index of the composite is found to be a weighted average of the properties of the individual constituents, without losing any other desirable properties ${ }^{36,79}$. 


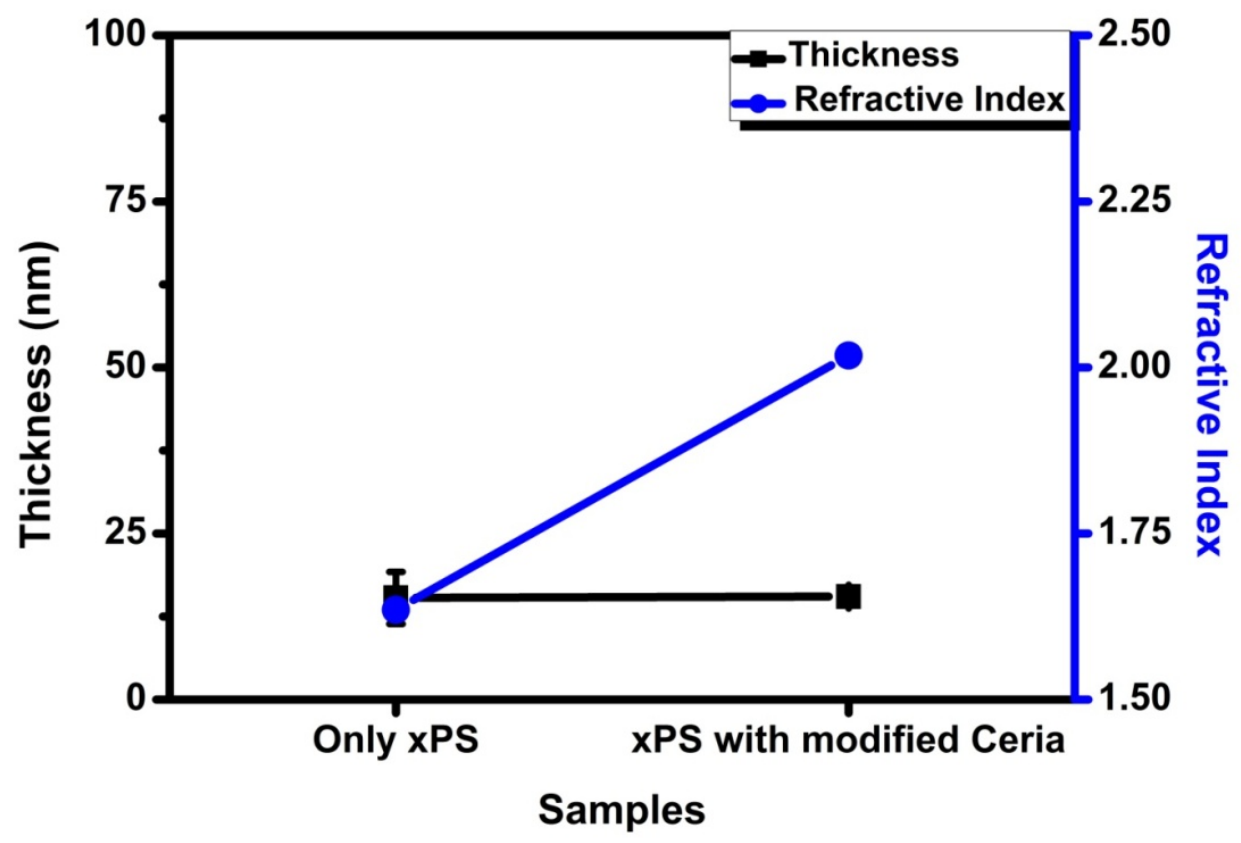

Figure 12: The thickness and refractive index measurement of polystyrene thin film and mps modified ceria - polystyrene thin films (xPS means crosslinked polystyrene, the error bar of the refractive index is too low to be visible)

\section{Conclusions}

In this study, different modalities have been employed to enhance the refractive index of polystyrene thin film. The embedding of the ceria nanoparticle on the surface of the polystyrene thin film leads to an increase in the refractive index from 1.59 to 1.612 . The use of cross-linkable polystyrene for the thin film preparation also has a significant role in protecting the polystyrene thin film, like in the case where the samples interact with volatile solvents like acetone or toluene, while they are being used for commercial applications and while preparing multilayer thin films. The bulk mixing of the ceria nanoparticles, in a way, has led to a uniform dispersion of the nanoparticles throughout and this opens up the area of higher refractive index polymer nanocomposite with a higher filler concentration in a polymer matrix.

The leaching of the base layers when multilayer coatings are prepared is a challenge and this could be overcome by the effective utilization of the cross-linking technique. The graded refractive index could be achieved by the multilayer coating with the subsequent variation in the concentration of the filler being added to the polymer matrix. This opens up a huge opportunity 
to engineer the refractive index thereby reducing the refractive index mismatch and thus leading to better energy efficient applications. We believe this work demonstrate that polymer thin films with higher refractive index could be achieved in a cost effective, efficient and reproducible manner in the future. This particular demonstration will be an effective platform for the refractive index engineering of polymer thin films with potentials for the photonics industry for the prospective applications.

\section{AUTHOR INFORMATION}

Corresponding Author

- Guillaume Vignaud, FRE CNRS 3744, IRDL, Univ. Bretagne Sud, F-56100, Lorient, France. Email: guillaume.vignaud@univ-ubs.fr

\section{Author Contributions}

The manuscript was written through contributions of all authors. All authors have given approval to the final version of the manuscript.

\section{Acknowledgement}

The authors acknowledge the financial support from CNRS, Republic of France and DST-Govt. of India for funding through Nanomission, FIST and PURSE programs, UGC-Govt. of India and the funding from BRNS- DAE (39/29/2015-BRNS/39009), Govt. of India.

8. References

(1) Xi, J.-Q.; Schubert, M. F.; Kim, J. K.; Schubert, E. F.; Chen, M.; Lin, S.-Y.; Liu, W.; Smart, J. A. Optical Thin-Film Materials with Low Refractive Index for Broadband Elimination of Fresnel Reflection. Nat. Photonics 2007, 1 (3), 176-179.

(2) Donati, G. Optical Imaging: Light Scattering on Tape. Nat. Photonics 2017, 11 (3), 141.

(3) Akasaki, I.; Amano, H.; Nakamura, S. The Nobel Prize in Physics 2014. R. Swedish Acad. Sci. 2014.

(4) Qiu, P.; Qiu, W.; Lin, Z.; Chen, H.; Ren, J.; Wang, J.-X.; Kan, Q.; Pan, J.-Q. Investigation of Beam Splitter in a Zero-Refractive-Index Photonic Crystal at the Frequency of Diraclike Point. Sci. Rep. 2017, 7 (1), 9588. 
(5) Šiffalovič, P.; Jergel, M.; Benkovičová, M.; Vojtko, A.; Nádaždy, V.; Ivančo, J.; Bodík, M.; Demydenko, M.; Majková, E. Towards New Multifunctional Coatings for Organic Photovoltaics. Sol. Energy Mater. Sol. Cells 2014, 125, 127-132.

(6) Berger, V. From Photonic Band Gaps to Refractive Index Engineering. Opt. Mater. (Amst). 1999, 11 (2), 131-142.

(7) Lü, C.; Yang, B. High Refractive Index Organic-inorganic Nanocomposites: Design, Synthesis and Application. J. Mater. Chem. 2009, 19 (19), 2884.

(8) Yang, B.; Shen, J.; Su, X.; Yang, H.; Cui, Z.; Lu, C. The Research on Syntheses and Properties of Novel Epoxy / Polymercaptan Curing Optical Resins with High Refractive Indices. Polymer (Guildf). 2001, 42, 10095-10100.

(9) Smith, D. R.; Pendry, J. B.; Wiltshire, M. C. K. Metamaterials and Negative Refractive Index. Science (80-. ). 2004, 305 (5685), 788-792.

(10) Liberal, I.; Engheta, N. Near-Zero Refractive Index Photonics. Nat. Photonics 2017, 11 (3), 149-158.

(11) Kana, J. B. K.; Vignaud, G.; Gibaud, A.; Maaza, M. Thermally Driven Sign Switch of Static Dielectric Constant of VO2 Thin Film. Opt. Mater. (Amst). 2016, 54, 165-169.

(12) Tai, K.; Yang, L.; Wang, Y. H.; Wynn, J. D.; Cho, A. Y. Drastic Reduction of Series Resistance in Doped Semiconductor Distributed Bragg Reflectors for Surface-emitting Lasers. Appl. Phys. Lett. 1990, 56 (25), 2496-2498.

(13) Lin, Y.-T.; Li, Y.-H.; Lei, I.-A.; Kuo, C.-Y.; Lee, C.-F.; Chiu, W.-Y.; Don, T.-M. Enhanced Reliability of LEDs Encapsulated with Surface-Modified Zirconia/Silicone Hybrids under Thermal Shock. Mater. Chem. Phys. 2018, 206, 136-143.

(14) Lee, L.-H.; Chen, W.-C. High-Refractive-Index Thin Films Prepared from Trialkoxysilane-Capped Poly(Methyl Methacrylate)-Titania Materials. Chem. Mater. 2001, 13 (3), 1137-1142.

(15) Shambat, G.; Ellis, B.; Majumdar, A.; Petykiewicz, J.; Mayer, M. A.; Sarmiento, T.; Harris, J.; Haller, E. E.; Vučković, J. Ultrafast Direct Modulation of a Single-Mode Photonic Crystal Nanocavity Light-Emitting Diode. Nat. Commun. 2011, 2, 539.

(16) Schneiderman, D. K.; Hillmyer, M. A. 50th Anniversary Perspective: There Is a Great Future in Sustainable Polymers. Macromolecules 2017, 50 (10), 3733-3749.

(17) Hong, M.; Chen, E. Y.-X. Chemically Recyclable Polymers: A Circular Economy Approach to Sustainability. Green Chem. 2017, 19 (16), 3692-3706.

(18) Higashihara, T.; Ueda, M. Recent Progress in High Refractive Index Polymers. Macromolecules 2015, 48 (7), 1915-1929.

(19) Carotenuto, G.; Longo, A.; Repetto, P.; Perlo, P.; Ambrosio, L. New Polymer Additives for Photoelectric Sensing. Sensors Actuators B Chem. 2007, 125 (1), 202-206. 
(20) Girault, P.; Lorrain, N.; Poffo, L.; Guendouz, M.; Lemaitre, J.; Carré, C.; Gadonna, M.; Bosc, D.; Vignaud, G. Integrated Polymer Micro-Ring Resonators for Optical Sensing Applications. J. Appl. Phys. 2015, 117 (10), 104504.

(21) Zhang, Q.; Fang, Z.; Cao, Y.; Du, H.; Wu, H.; Beuerman, R.; Chan-Park, M. B.; Duan, H.; $\mathrm{Xu}, \mathrm{R}$. High Refractive Index Inorganic-organic Interpenetrating Polymer Network (IPN) Hydrogel Nanocomposite toward Artificial Cornea Implants. ACS Macro Lett. 2012, 1 (7), 876-881.

(22) Zhang, Q.; Su, K.; Chan-Park, M. B.; Wu, H.; Wang, D.; Xu, R. Development of High Refractive ZnS/PVP/PDMAA Hydrogel Nanocomposites for Artificial Cornea Implants. Acta Biomater. 2014, 10 (3), 1167-1176.

(23) Rogers, H. G.; Gaudiana, R. A.; Hollinsed, W. C.; Kalyanaraman, P. S.; Manello, J. S.; Mcgowan, C.; Minns, R. A.; Sahatjian, R. Highly Amorphous, Birefringent, Para-Linked Aromatic Polyamides. Macromolecules 1985, 18 (6), 1058-1068.

(24) Yang, C. J.; Jenekhe, S. A. Effects of Structure on Refractive Index of Conjugated Polyimines. Chem. Mater. 1994, 6 (2), 196-203.

(25) Caglar, M.; Ilican, S.; Caglar, Y.; Yakuphanoglu, F. Electrical Conductivity and Optical Properties of ZnO Nanostructured Thin Film. Appl. Surf. Sci. 2009, 255 (8), 4491-4496.

(26) Sugiyama, T. OPTICAL NONLINEARITY OF CONJUGATED POLYMERS. 1989, 28, 323-328.

(27) Gaudiana, R. A.; Minns, R. A. High Refractive Index Polymers. J. Macromol. Sci. Part A - Chem. 1991, 28 (9) (November 2012), 831-842.

(28) Vignaud, G.; Chebil, M. S.; Bal, J. K.; Delorme, N.; Beuvier, T.; Grohens, Y.; Gibaud, A. Densification and Depression in Glass Transition Temperature in Polystyrene Thin Films. Langmuir 2014, 30 (39), 11599-11608.

(29) Unni, A. B.; Vignaud, G.; Chapel, J. P.; Giermanska, J.; Bal, J. K.; Delorme, N.; Beuvier, T.; Thomas, S.; Grohens, Y.; Gibaud, A. Probing the Density Variation of Confined Polymer Thin Films via Simple Model-Independent Nanoparticle Adsorption. Macromolecules 2017, 50 (3), 1027-1036.

(30) Huang, T.-T.; Cheng, S.-W.; Tsai, C.-L.; Liou, G.-S. Optically Isotropic, Colorless, and Flexible PITEs/TiO2 and $\mathrm{ZrO} 2$ Hybrid Films with Tunable Refractive Index, Abbe Number, and Memory Properties. Sci. Rep. 2017, 7 (1), 7978 .

(31) Cheng, Y.; Lu, C.; Yang, B. A Review on High Refractive Index Nanocomposites for Optical Applications. Recent Patents Mater. Sci. 2011, 4 (1), 15-27.

(32) Liu, J.; Ueda, M. High Refractive Index Polymers: Fundamental Research and Practical Applications. J. Mater. Chem. 2009, 19 (47), 8907-8919.

(33) Singh, H. Structural and Optical Study of Nanostructured Se80-XTe20Sbx $(0 \leq X \leq 12)$ Thin Films. Nano-Structures \& Nano-Objects 2017, 10, 192-197. 
(34) Lenart, W. R.; Hore, M. J. A. Structure-property Relationships of Polymer-Grafted Nanospheres for Designing Advanced Nanocomposites. Nano-Structures \& Nano-Objects 2017.

(35) Tao, P.; Li, Y.; Rungta, A.; Viswanath, A.; Gao, J.; Benicewicz, B. C.; Siegel, R. W.; Schadler, L. S. TiO2 Nanocomposites with High Refractive Index and Transparency. J. Mater. Chem. 2011, 21 (46), 18623.

(36) Incel, A.; Güner, T.; Parlak, O.; Demir, M. M. Null Extinction of Ceria@ silica Hybrid Particles: Transparent Polystyrene Composites. ACS Appl. Mater. Interfaces 2015, 7 (49), 27539-27546.

(37) Chen, F.; Clough, A.; Reinhard, B. M.; Grinstaff, M. W.; Jiang, N.; Koga, T.; Tsui, O. K. C. Glass Transition Temperature of Polymer-Nanoparticle Composites: Effect of PolymerParticle Interfacial Energy. Macromolecules 2013, 46 (11), 4663-4669 .

(38) Eriksson, M.; Goossens, H.; Peijs, T. Influence of Drying Procedure on Glass Transition Temperature of PMMA Based Nanocomposites. Nanocomposites 2015, 1 (1), 36-45.

(39) Eslami, H.; Rahimi, M.; Müller-Plathe, F. Molecular Dynamics Simulation of a Silica Nanoparticle in Oligomeric Poly (Methyl Methacrylate): A Model System for Studying the Interphase Thickness in a Polymer-nanocomposite via Different Properties. Macromolecules 2013, 46 (21), 8680-8692.

(40) Roldughin, V. I.; Serenko, O. A.; Getmanova, E. V; Novozhilova, N. A.; Nikifirova, G. G.; Buzin, M. I.; Chvalun, S. N.; Ozerin, A. N.; Muzafarov, A. M. Effect of Hybrid Nanoparticles on Glass Transition Temperature of Polymer Nanocomposites. Polym. Compos. 2016, 37 (7), 1978-1990.

(41) Zhu, L.; Wang, X.; Gu, Q.; Chen, W.; Sun, P.; Xue, G. Confinement-Induced Deviation of Chain Mobility and Glass Transition Temperature for Polystyrene/Au Nanoparticles. Macromolecules 2013, 46 (6), 2292-2297 ..

(42) Boucher, V. M.; Cangialosi, D.; Alegría, A.; Colmenero, J.; Pastoriza-Santos, I.; LizMarzan, L. M. Physical Aging of Polystyrene/Gold Nanocomposites and Its Relation to the Calorimetric Tg Depression. Soft Matter 2011, 7 (7), 3607 .

(43) Mukherjee, R.; Das, S.; Das, A.; Sharma, S. K.; Raychaudhuri, A. K.; Sharma, A. Stability and Dewetting of Metal Nanoparticle Filled Thin Polymer Films: Control of Instability Length Scale and Dynamics. ACS Nano 2010, 4 (7), 3709-3724.

(44) Chandran, S.; Begam, N.; Padmanabhan, V.; Basu, J. K. Confinement Enhances Dispersion in Nanoparticle-Polymer Blend Films. Nat. Commun. 2014, 5 (May), 1-9.

(45) Matsumoto, S.; Ishii, T.; Wada, M.; Kuwahara, Y.; Ogata, T.; Nagaoka, S.; Takafuji, M.; Ihara, H. Facile Preparation of High Refractive Index Polymer Films Composited with a Tungstophosphoric Acid. Mater. Lett. 2017, 190, 236-239 .

(46) Li, C.; Colella, N. S.; Watkins, J. J. Low-Temperature Fabrication of Mesoporous Titanium Dioxide Thin Films with Tunable Refractive Indices for One-Dimensional 
Photonic Crystals and Sensors on Rigid and Flexible Substrates. ACS Appl. Mater. Interfaces 2015, 7 (24), 13180-13188.

(47) Krogman, K. C.; Druffel, T.; Sunkara, M. K. Anti-Reflective Optical Coatings Incorporating Nanoparticles. Nanotechnology 2005, 16 (7) .

(48) Takahashi, S.; Hotta, S.; Watanabe, A.; Idota, N.; Matsukawa, K.; Sugahara, Y. Modification of TiO2nanoparticles with Oleyl Phosphate via Phase Transfer in the Toluene-water System and Application of Modified Nanoparticles to Cyclo-OlefinPolymer-Based Organic-inorganic Hybrid Films Exhibiting High Refractive Indices. ACS Appl. Mater. Interfaces 2017, 9 (2), 1907-1912.

(49) Nolte, A. J.; Rubner, M. F.; Cohen, R. E. Creating Effective Refractive Index Gradients within Polyelectrolyte Multilayer Films: Molecularly Assembled Rugate Filters. Langmuir 2004, 20 (8), 3304-3310.

(50) Al Akhrass, S.; Gal, F.; Damiron, D.; Alcouffe, P.; Hawker, C. J.; Cousin, F.; Carrot, G.; Drockenmuller, E. Design of Crosslinked Hybrid Multilayer Thin Films from AzidoFunctionalized Polystyrenes and Platinum Nanoparticles. Soft Matter 2009, 5 (3), 586 ..

(51) Kurt, P.; Banerjee, D.; Cohen, R. E.; Rubner, M. F. Structural Color via Layer-by-Layer Deposition: Layered Nanoparticle Arrays with near-UV and Visible Reflectivity Bands. J. Mater. Chem. 2009, 19 (47), 8920-8927.

(52) Hammond, P. T. Form and Function in Multilayer Assembly: New Applications at the Nanoscale. Adv. Mater. 2004, 16 (15), 1271-1293.

(53) Chiu, F.-C.; Lai, C.-M. Optical and Electrical Characterizations of Cerium Oxide Thin Films. J. Phys. D. Appl. Phys. 2010, 43 (7), 075104.

(54) Parlak, O.; Demir, M. M. Toward Transparent Nanocomposites Based on Polystyrene Matrix and PMMA-Grafted CeO2 Nanoparticles. ACS Appl. Mater. Interfaces 2011, 3 (11), 4306-4314.

(55) Itoh, T.; Uchida, T.; Izu, N.; Matsubara, I.; Shin, W. Effect of Core-shell Ceria/Poly (Vinylpyrrolidone)(PVP) Nanoparticles Incorporated in Polymer Films and Their Optical Properties. Materials (Basel). 2013, 6 (6), 2119-2129.

(56) Beena Unni, A.; Vignaud, G.; Bal, J. K.; Delorme, N.; Beuvier, T.; Thomas, S.; Grohens, Y.; Gibaud, A. Solvent Assisted Rinsing: Stability/Instability of Ultrathin Polymer Residual Layer. Macromolecules 2016, 49 (5), 1807-1815.

(57) El Ouakili, A.; Vignaud, G.; Balnois, E.; Bardeau, J. F.; Grohens, Y. Multiple Glass Transition Temperatures of Polymer Thin Films as Probed by Multi-Wavelength Ellipsometry. Thin Solid Films 2011, 519 (6), 2031-2036.

(58) Bal, J. K.; Beuvier, T.; Unni, A. B.; Chavez Panduro, E. A.; Vignaud, G.; Delorme, N.; Chebil, M. S.; Grohens, Y.; Gibaud, A. Stability of Polymer Ultrathin Films $(<7 \mathrm{Nm})$ Made by a Top-down Approach. ACS Nano 2015, 9 (8), 8184-8193. 
(59) Jiang, N.; Cheung, J.; Guo, Y.; Endoh, M. K.; Koga, T.; Yuan, G.; Satija, S. K. Stability of Adsorbed Polystyrene Nanolayers on Silicon Substrates. Macromol. Chem. Phys. 2018, 219 (3), 1-10.

(60) Lai, J. H. An Investigation of Spin Coating of Electron Resists. Polym. Eng. Sci. 1979, 19 (15), 1117-1121.

(61) Siretanu, I.; Chapel, J. P.; Drummond, C. Water-Ions Induced Nanostructuration of Hydrophobic Polymer Surfaces. ACS Nano 2011, 5 (4), 2939-2947.

(62) Bang, J.; Bae, J.; Lówenhielm, P.; Spiessberger, C.; Given-Beck, S. A.; Russell, T. P.; Hawker, C. J. Facile Routes to Patterned Surface Neutralization Layers for Block Copolymer Lithography. Adv. Mater. 2007, 19 (24), 4552-4557 .

(63) Parlak, O.; Demir, M. M. Anomalous Transmittance of Polystyrene-ceria Nanocomposites at High Particle Loadings. J. Mater. Chem. C 2013, 1 (2), 290-298 .

(64) Demydenko, M.; Protsenko, S.; Siffalovic, P. Null-Ellipsometry Investigations of the Optical Properties and Diffusion Processes in Spin-Valve Structures Based on Co and $\mathrm{Cu}$. Thin Solid Films 2012, 520 (17), 5722-5726.

(65) Ton-That, C.; Shard, A. G.; Bradley, R. H. Thickness of Spin-Cast Polymer Thin Films Determined by Angle-Resolved XPS and AFM Tip-Scratch Methods. Langmuir 2000, 16 (5), 2281-2284.

(66) Li, Y.; Pham, J. Q.; Johnston, K. P.; Green, P. F. Contact Angle of Water on Polystyrene Thin Films: Effects of CO2 Environment and Film Thickness. Langmuir 2007, 23 (19), 9785-9793.

(67) Ata, S.; Muramatsu, M.; Takeda, J.; Ohdaira, T.; Suzuki, R.; Ito, K.; Kobayashi, Y.; Ougizawa, T. Free Volume Behavior in Spincast Thin Film of Polystyrene by Energy Variable Positron Annihilation Lifetime Spectroscopy. Polymer (Guildf). 2009, 50 (14), 3343-3346.

(68) Ata, S.; Kuboyama, K.; Ito, K.; Kobayashi, Y.; Ougizawa, T. Anisotropy and Densi Fi Cation of Polymer Ultrathin Fi Lms as Seen by Multi-Angle Ellipsometry and X-Ray Re Fl Ectometry. 2012, 53, 1028-1033.

(69) Mondal, M. H.; Mukherjee, M. Study of Thickness Dependent Density in Ultrathin Water Soluble Polymer Films. 2009, 732-736.

(70) Perlich, J.; Metwalli, E.; Schulz, L.; Georgii, R.; Müller-Buschbaum, P. Solvent Content in Thin Spin-Coated Polystyrene Homopolymer Films. Macromolecules 2008, 42 (1), 337-344.

(71) Reiter, G.; Hamieh, M.; Damman, P.; Sclavons, S.; Gabriele, S.; Vilmin, T.; Raphaël, E. Residual Stresses in Thin Polymer Films Cause Rupture and Dominate Early Stages of Dewetting. Nat. Mater. 2005, 4 (10), 754.

(72) Kanaya, T.; Miyazaki, T.; Watanabe, H.; Nishida, K.; Yamano, H.; Tasaki, S.; Bucknall, 
D. B. Annealing Effects on Thickness of Polystyrene Thin Films as Studied by Neutron Reflectivity. Polymer (Guildf). 2003, 44 (14), 3769-3773 .

(73) Maldovan, M.; Bockstaller, M. R.; Thomas, E. L.; Carter, W. C. Validation of the Effective-Medium Approximation for the Dielectric Permittivity of Oriented Nanoparticle-Filled Materials: Effective Permittivity for Dielectric Nanoparticles in Multilayer Photonic Composites. Appl. Phys. B Lasers Opt. 2003, 76 (8), 877-884 .

(74) Lenhart, J. L.; Wu, W. Influence of Cross-Link Density on the Thermal Properties of Thin Polymer Network Films. Langmuir 2003, 19 (22), 4863-4865.

(75) Carroll, G. T.; Sojka, M. E.; Lei, X.; Turro, N. J.; Koberstein, J. T. Photoactive Additives for Cross-Linking Polymer Films: Inhibition of Dewetting in Thin Polymer Films. Langmuir 2006, 22 (18), 7748-7754.

(76) Shokuhfar, A.; Arab, B. The Effect of Cross Linking Density on the Mechanical Properties and Structure of the Epoxy Polymers: Molecular Dynamics Simulation. J. Mol. Model. 2013, 19 (9), 3719-3731.

(77) Xue, L.; Han, Y. Inhibition of Dewetting of Thin Polymer Films. Prog. Mater. Sci. 2012, 57 (6), 947-979.

(78) Akhrass, S. Al; Ostaci, R. V.; Grohens, Y.; Drockenmuller, E.; Reiter, G. Influence of Progressive Cross-Linking on Dewetting of Polystyrene Thin Films. Langmuir 2008, 24 (5), 1884-1890.

(79) Wang, Z.; Lu, Z.; Mahoney, C.; Yan, J.; Ferebee, R.; Luo, D.; Matyjaszewski, K.; Bockstaller, M. R. Transparent and High Refractive Index Thermoplastic Polymer Glasses Using Evaporative Ligand Exchange of Hybrid Particle Fillers. 2017. 


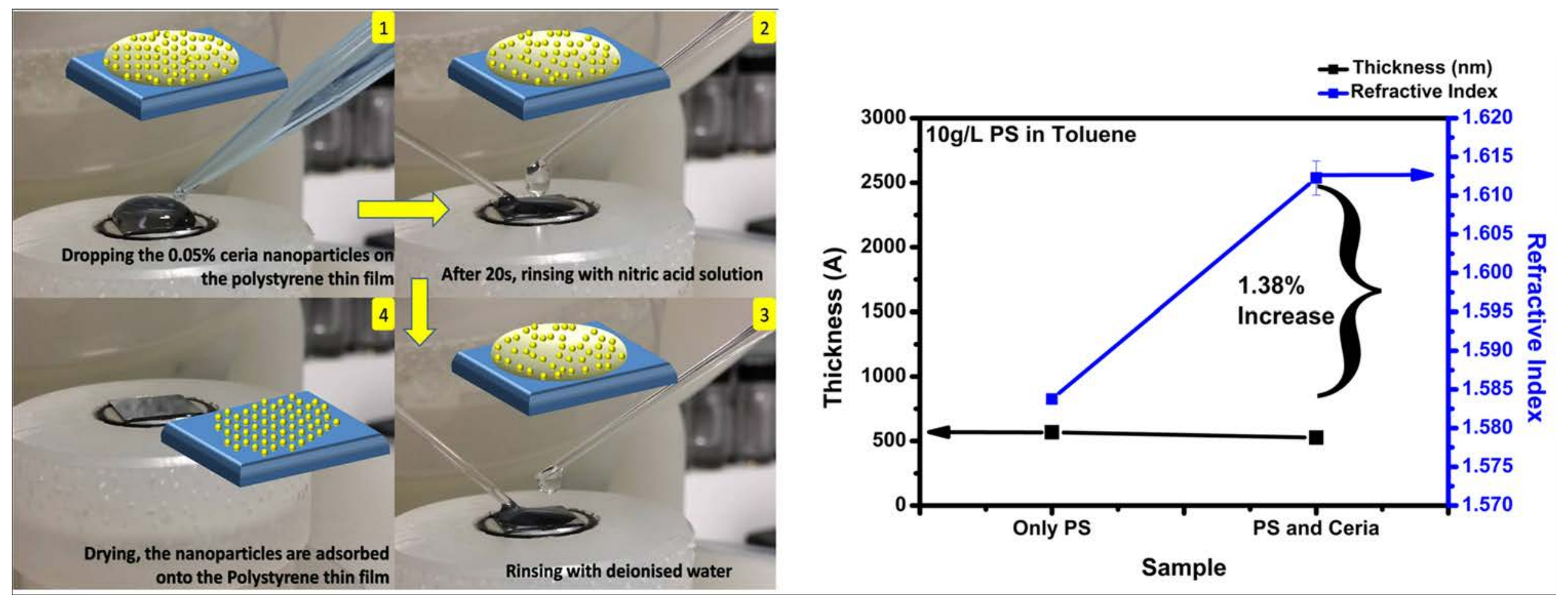




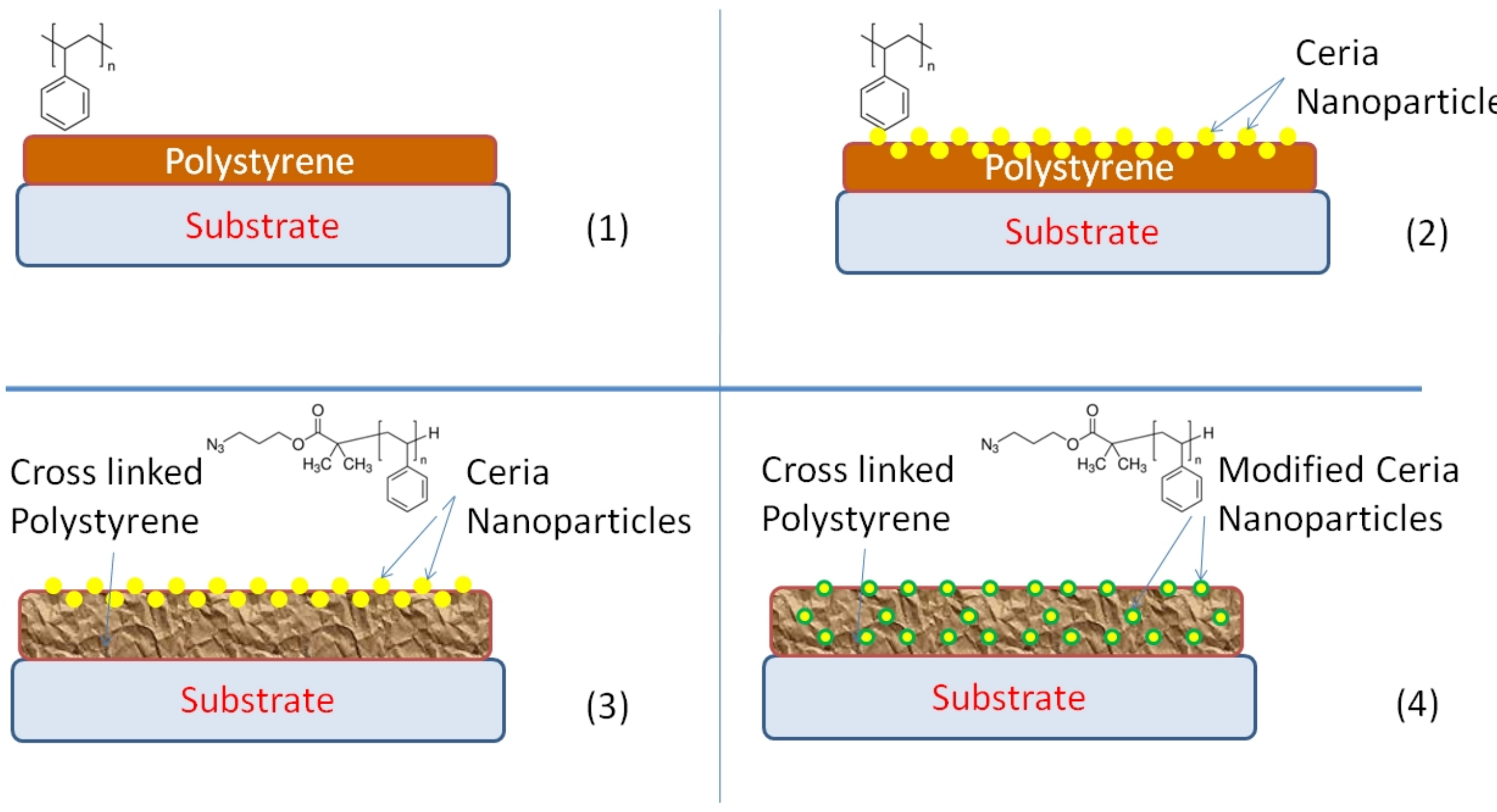




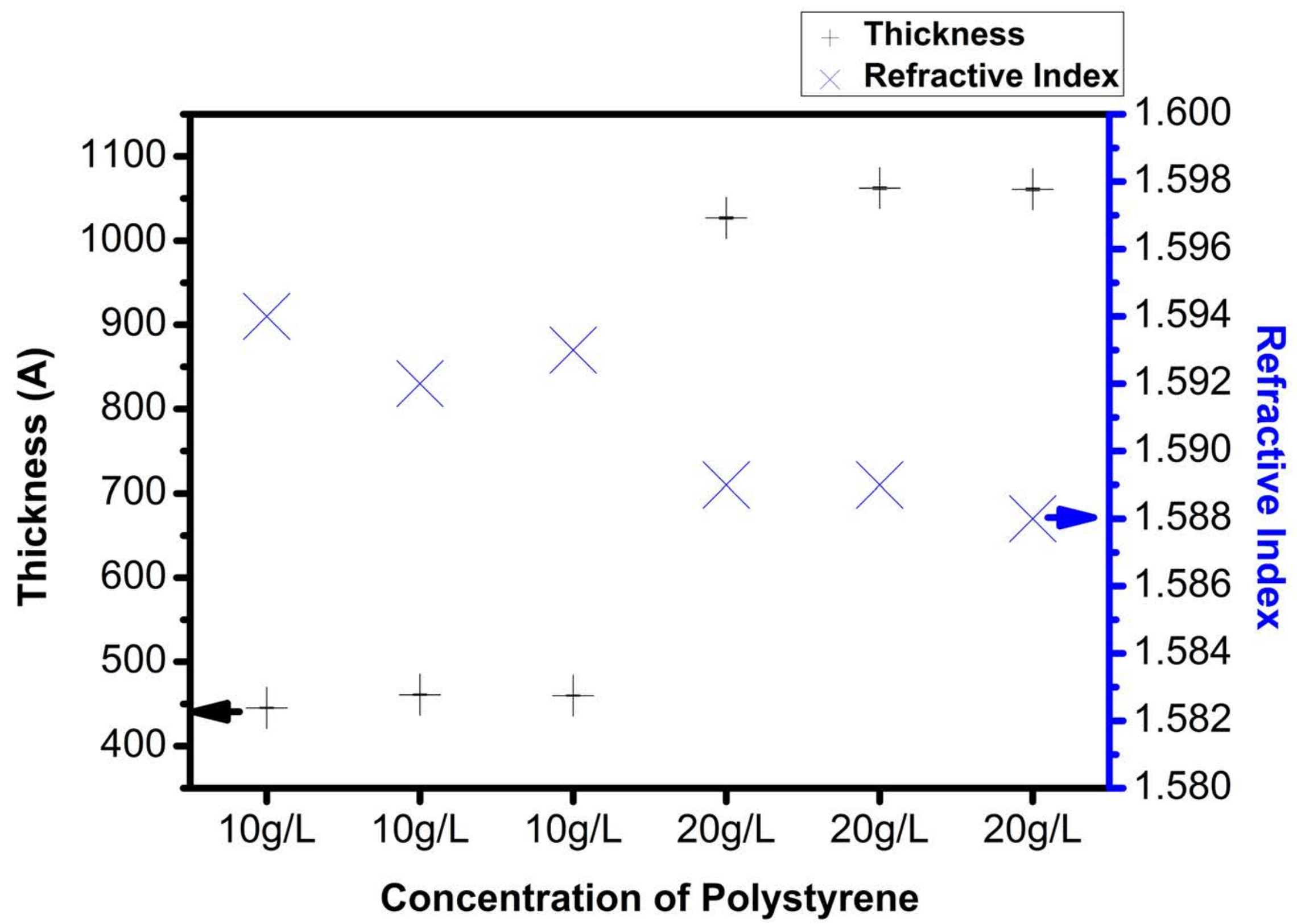




\section{Lower \\ Concentration \\ Lower Interchain \\ Entanglement \\ Higher \\ Orientation}

Higher refractive index Higher density 


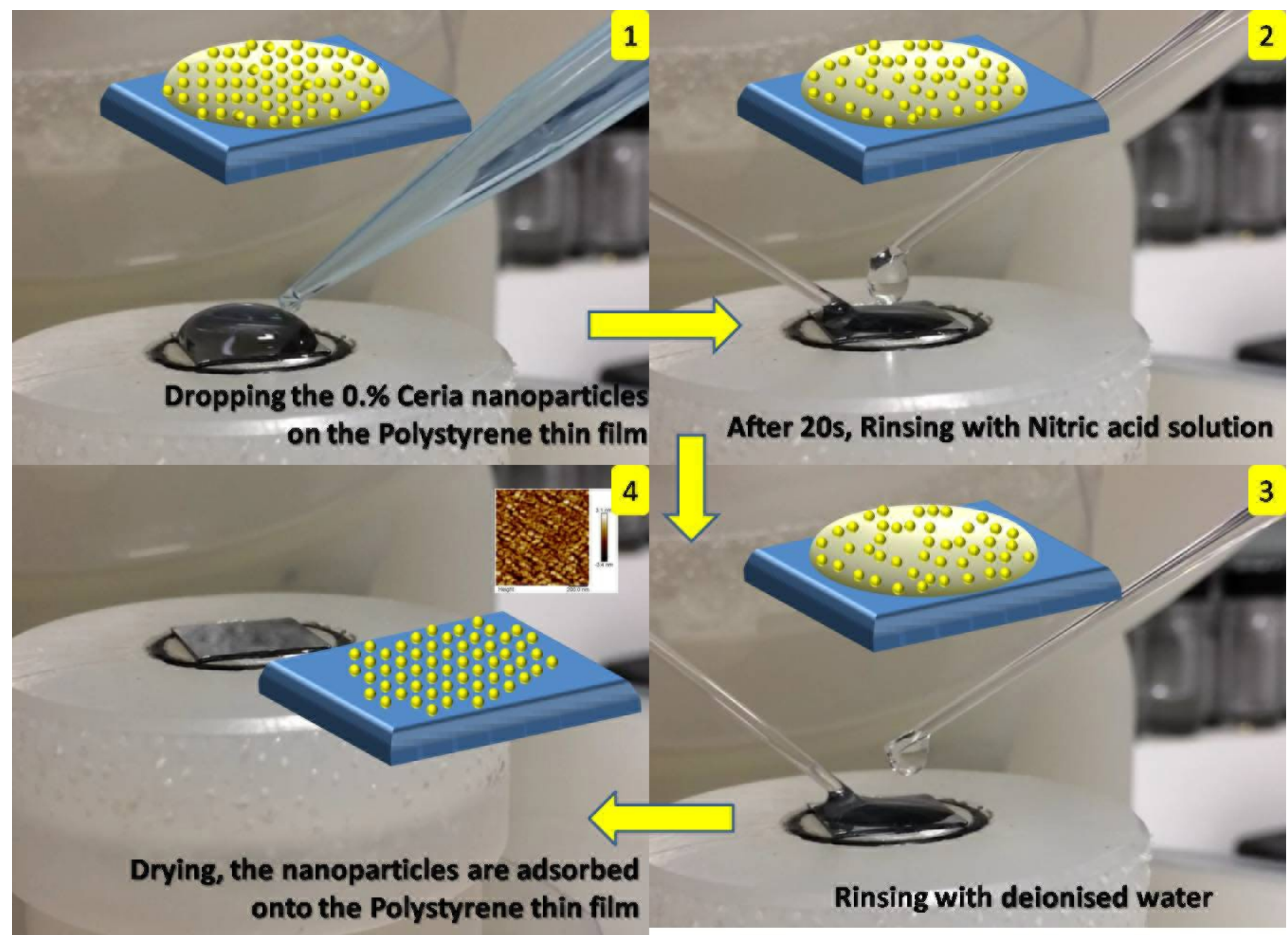


- Thickness (nm)

-Refractive Index

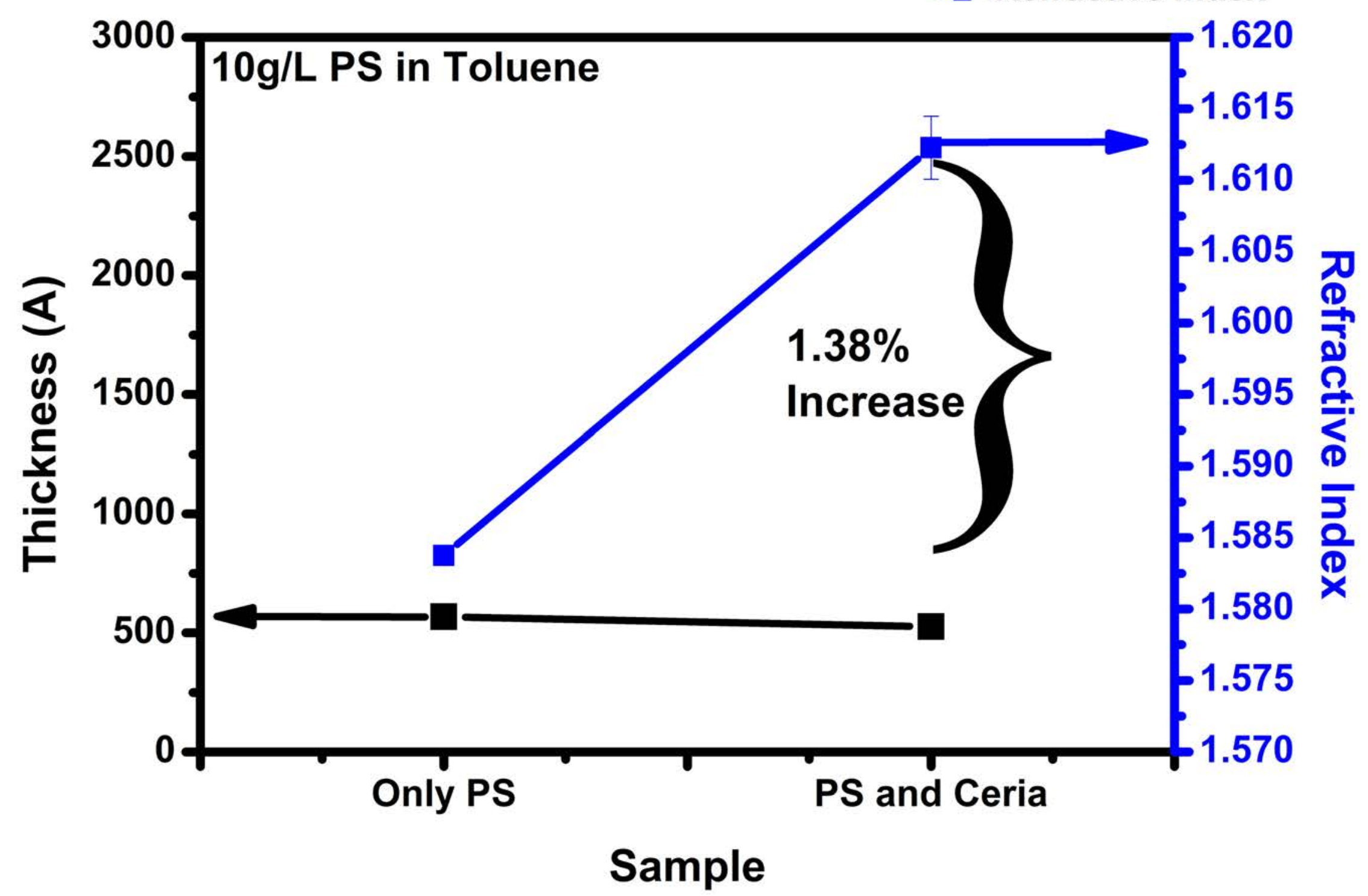




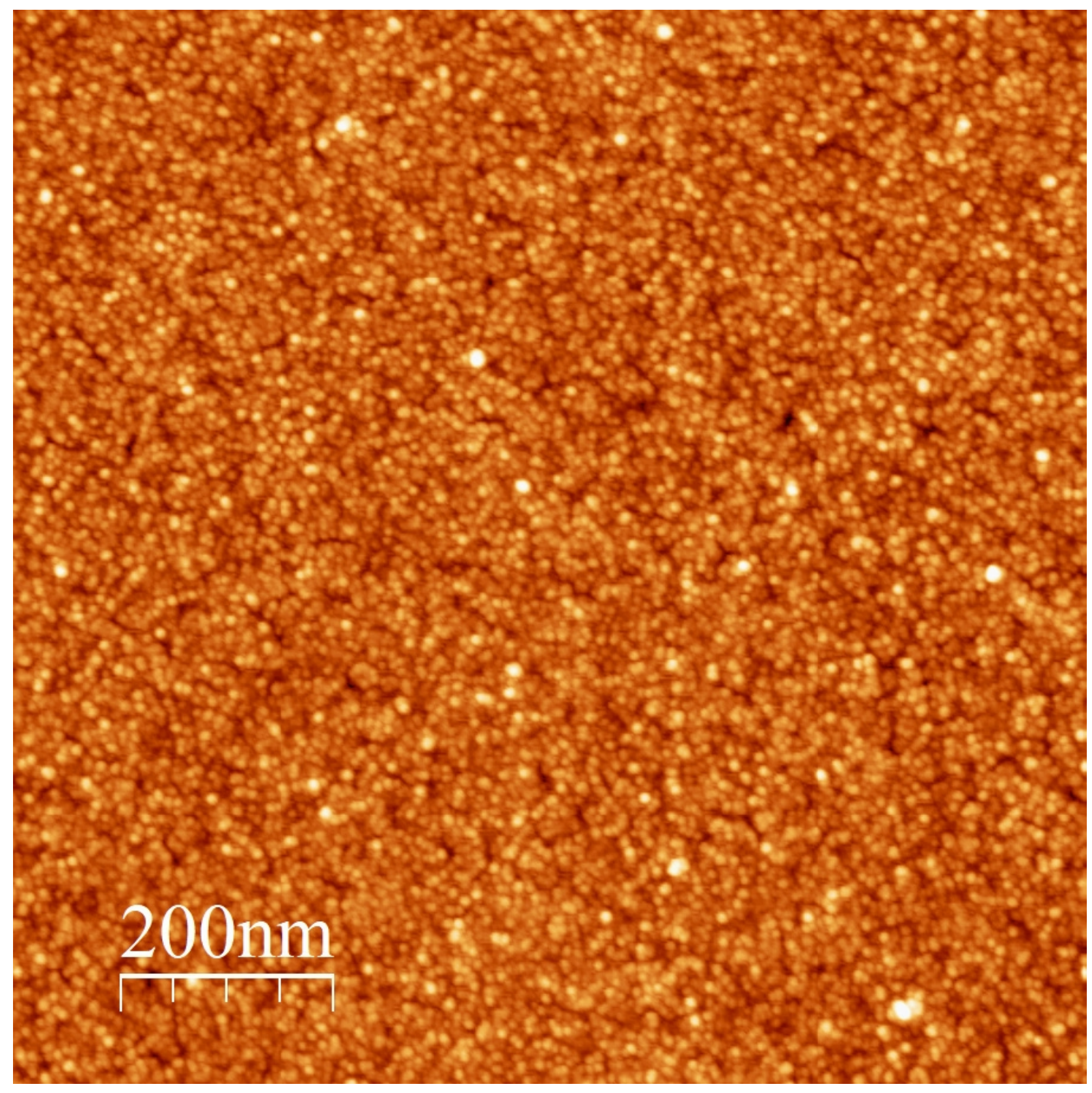



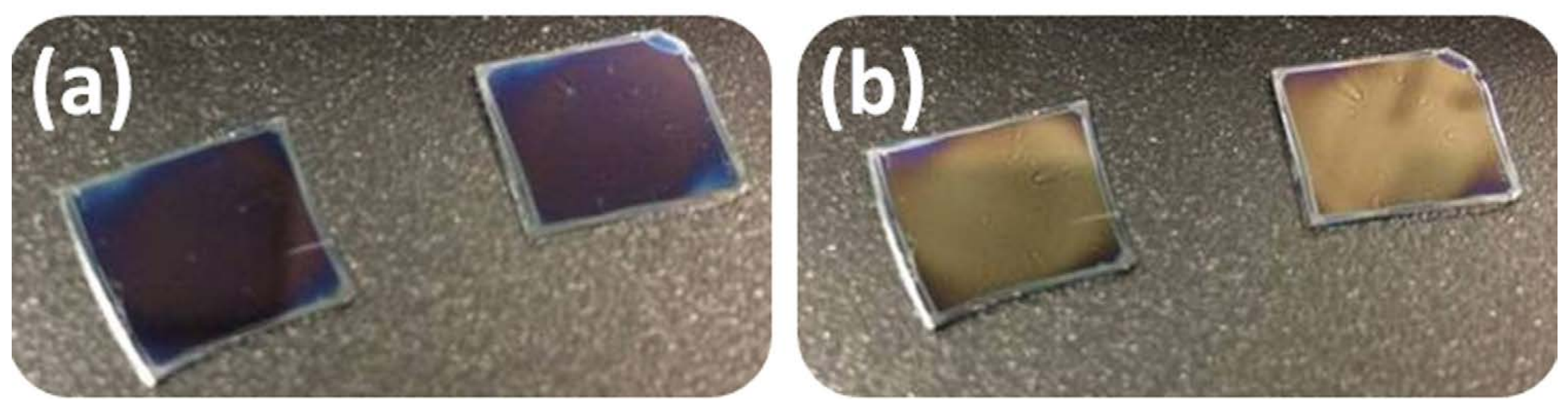


\section{Polymer-}

before crosslinking

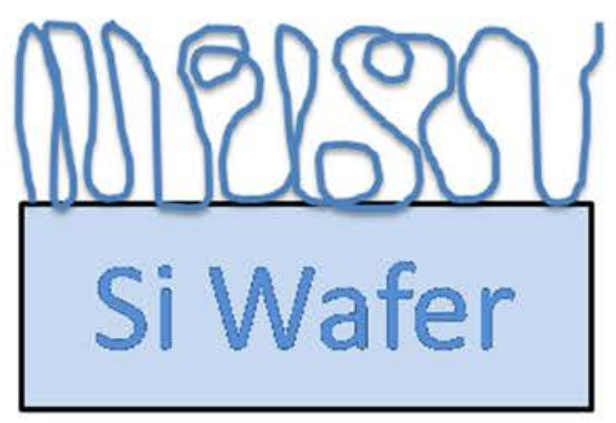

UV Curing

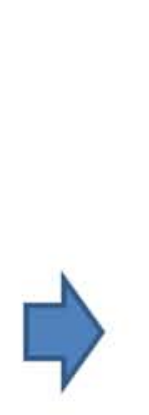

1

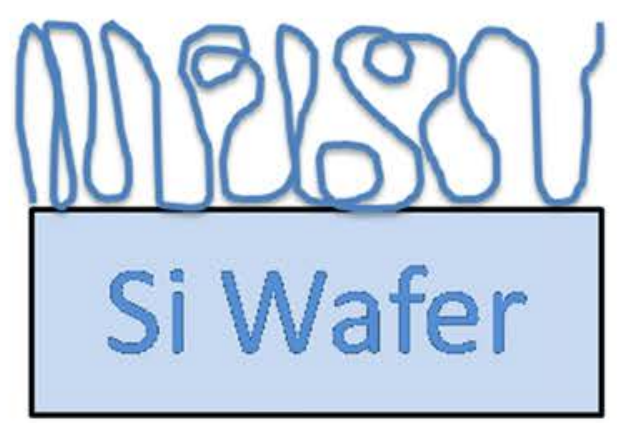

Polymerafter crosslinking

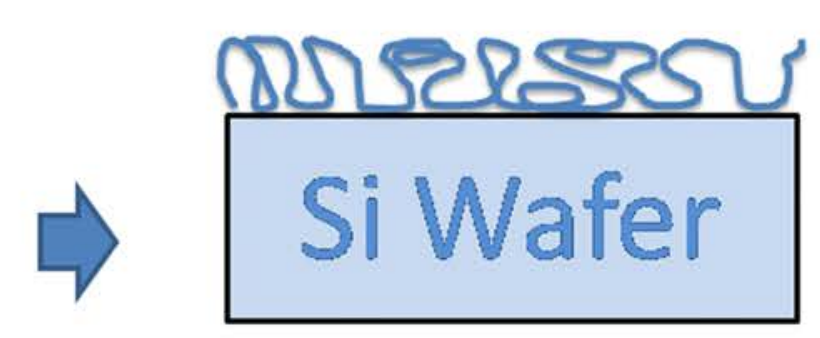




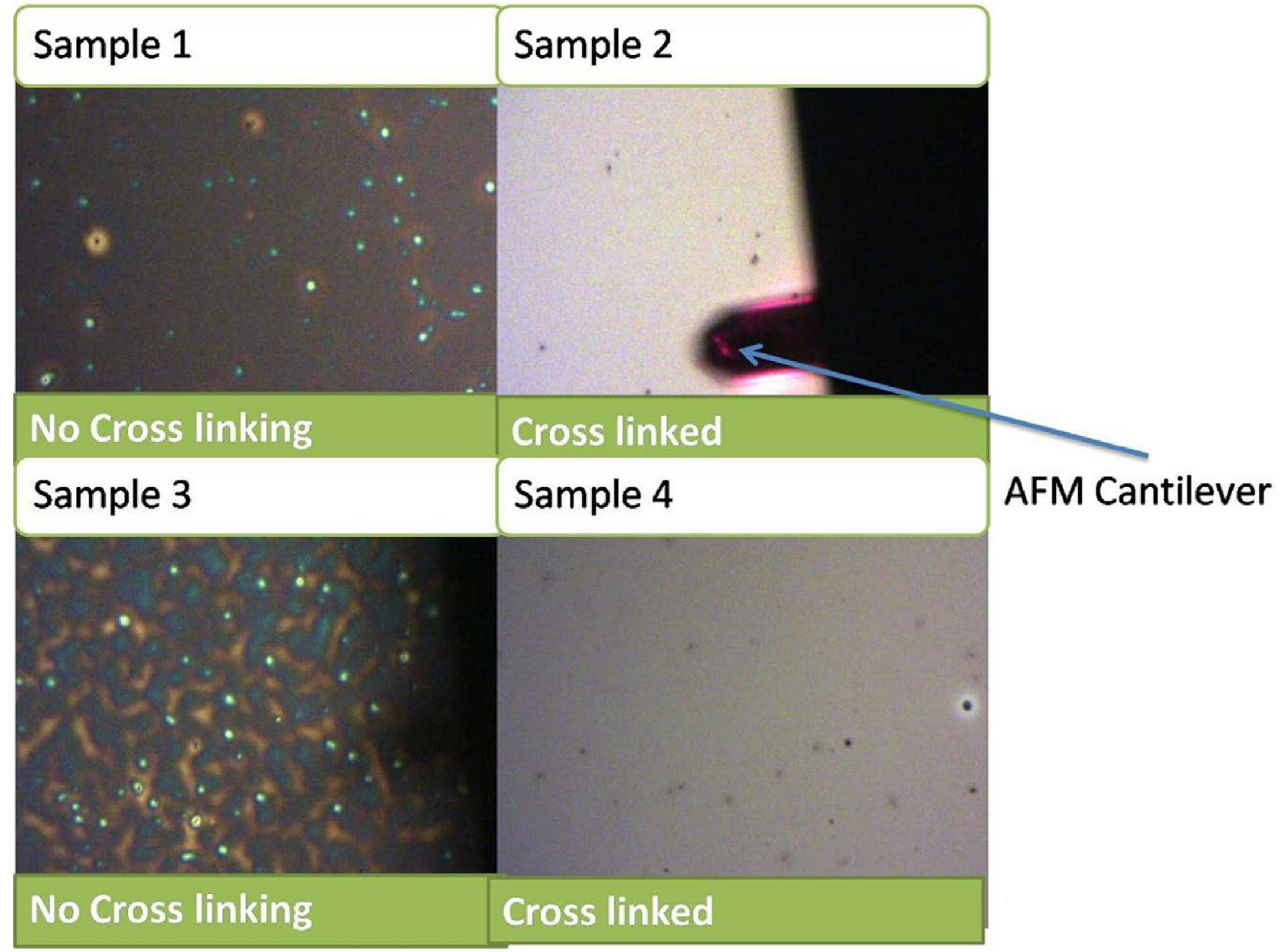




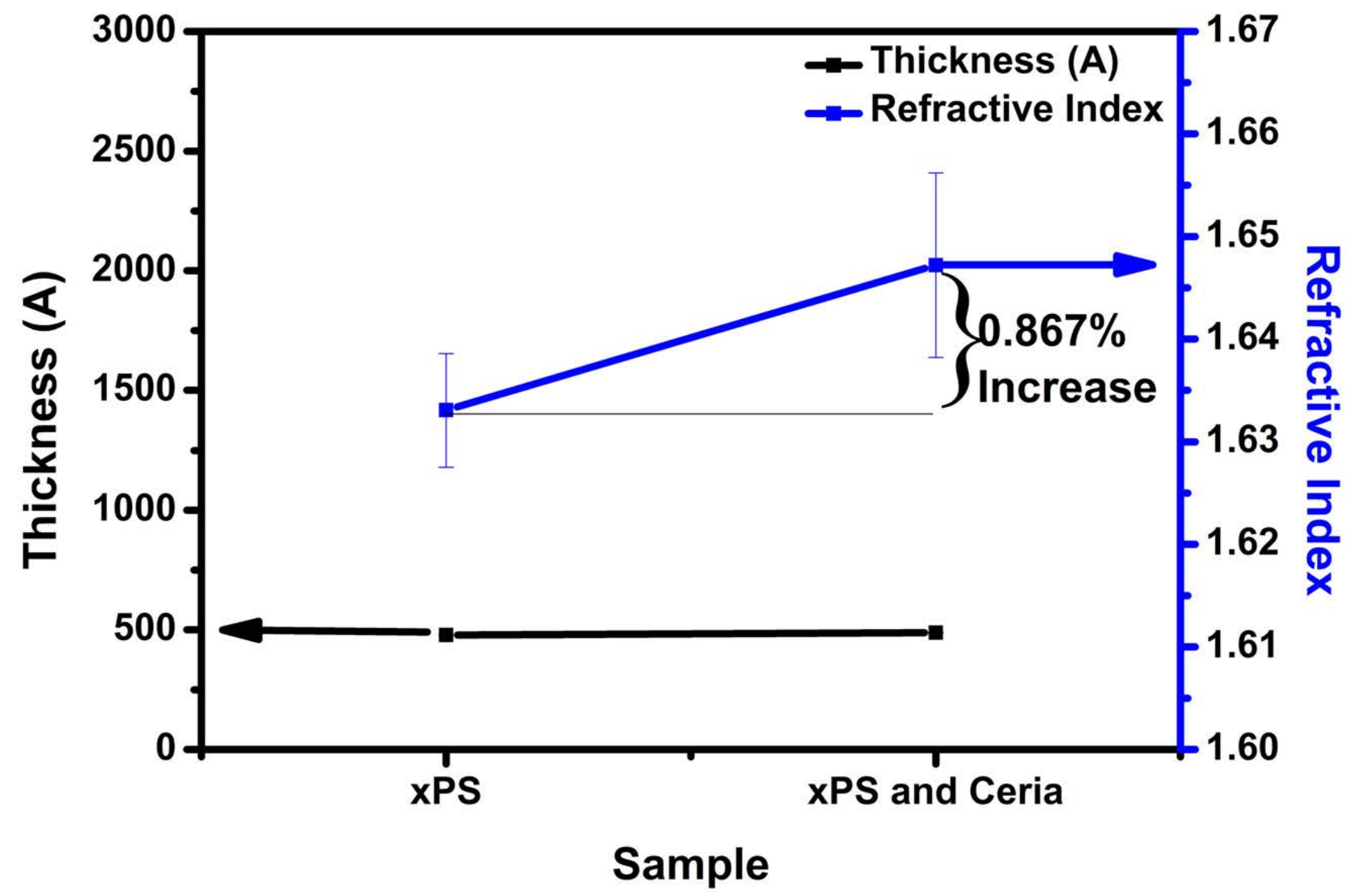




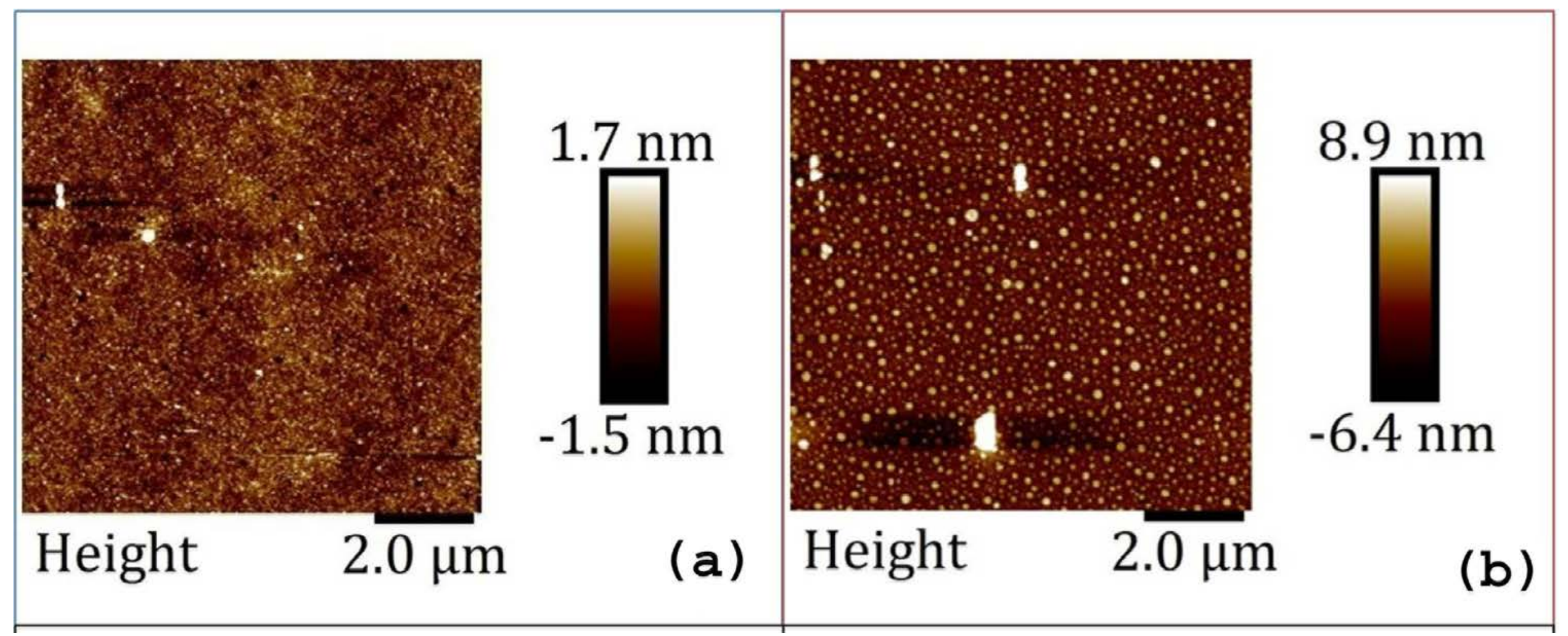




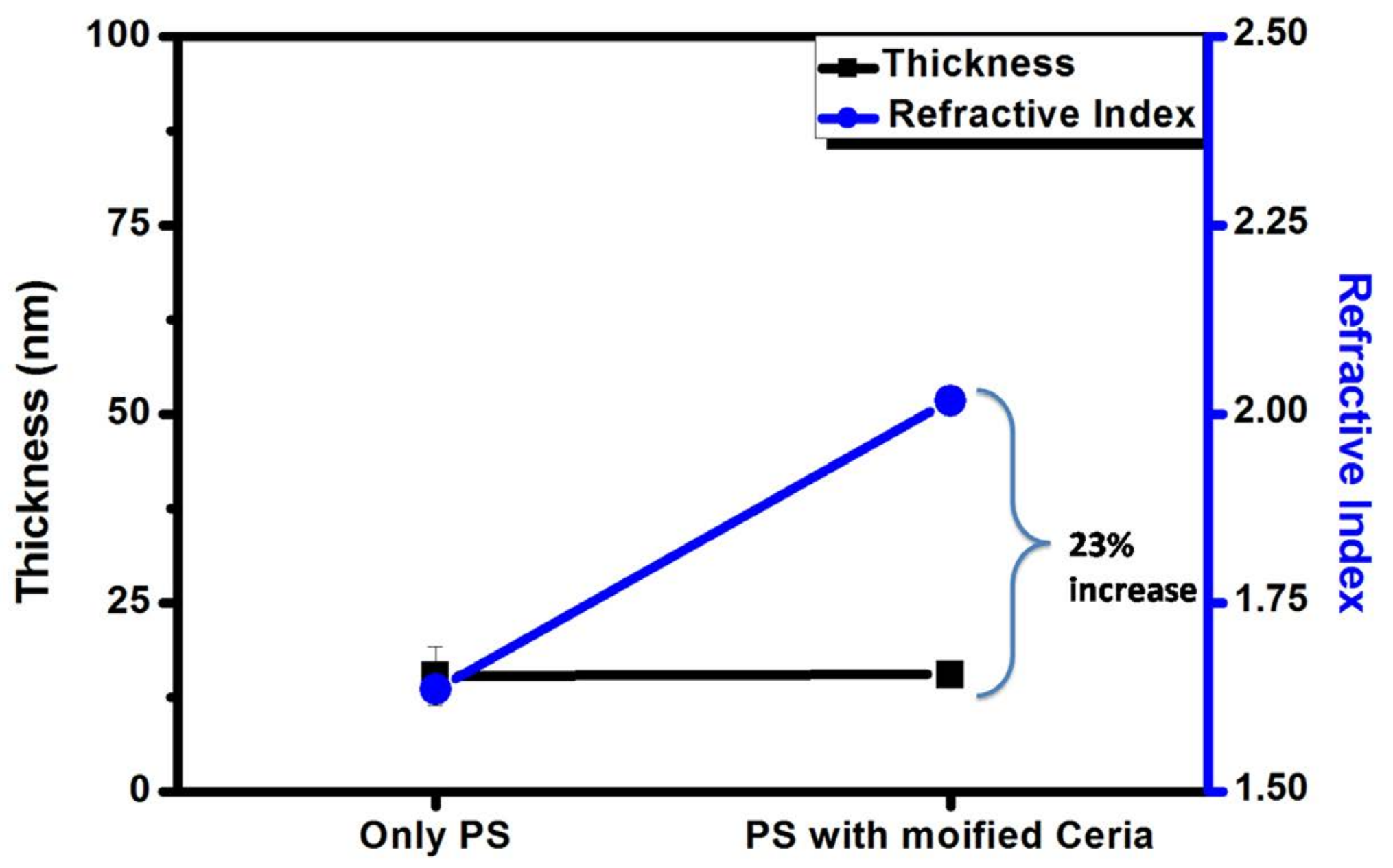

